\title{
Conceptos trascendentales, reflexión y juicio. Sobre el § 12 de la Kritik der reinen Vernunft*
}

\author{
AlejANDRo G. Vigo \\ Universidad de Navarra \\ avigo@unav.es
}

Resumen: El presente trabajo ofrece una reconstrucción de la posición que
Kant elabora en el $\S 12$ de la Kritik der reinen Vernunft, con el objetivo de
incorporar en su propia concepción la temática nuclear propia de la doctrina
de los atributos trascendentales del ser elaborada por la tradición metafísica.
El alcance sistemático de la recontextualización llevada a cabo por Kant se
comprende cuando se pone en conexión la temática del $\S 12$ con la con-
cepción kantiana relativa a los presupuestos reflexivos del juicio, tal como
ésta aparece desarrollada en el texto de la "Anfibología de los conceptos de
reflexión". En tal sentido, el este artículo constituye la continuación natural
de uno anterior en el cual se discute la concepción que Kant elabora en la
"Anfibología". La interpretación ofrecida aquí apunta, entre otras cosas, a po-
ner de relieve que los criterios lógicos que Kant tematiza en el $\S 12$ cumplen
funciones regulativas que orientan procesos de tipo reflexivo, entre los cuales
destacan particularmente aquellos que subyacen a la formación originaria de
conceptos empíricos.

Palabras clave: conceptos trascendentales, conceptos empíricos, juicio, reflexión

\begin{abstract}
This paper gives a reconstruction of the view Kant develops in the $\S 12$ of his Kritik der reinen Vernunft trying to incorporate in his own conception the thematic core of the traditional metaphysical doctrine of the transcendental attributes of being. The systematic motivation and scope of Kant's view in $\S 12$ is better understood in connection with his explanation of the role of reflexive process underlying objective judgements in the "Amphiboly of Concepts of Reflexion", as discussed in an earlier paper by the author. The interpretation offered here stresses the fact that the logical criteria Kant discusses in $\S 12$ fulfill regulative functions guiding reflexive processes, especially in the case of the original formation of empirical concepts.
\end{abstract}

Key words: transcendental concepts, empirical concepts, judgement, reflexion

${ }^{*}$ El presente trabajo fue escrito en el marco de un proyecto de investigación sobre "Juicio y objetividad categorial de Kant al neokantismo", financiado por Fondecyt (Chile) (Proyecto 1050871). Agradezco a los árbitros anónimos de Diánoia por sus críticas y sugerencias. No creo haber podido hacer justicia a todas, pero algunas de ellas me ayudaron a mejorar en varios puntos la presentación de mis argumentos. Muy especialmente, deseo agradecer al Prof. Alberto Rosales (Caracas), que, con su admirable penetración filosófica, captó con toda precisión el nú- 


\section{Introducción}

En un trabajo precedente, ${ }^{1}$ he discutido la posición que Kant elabora con respecto al problema de las relaciones entre reflexión y juicio, en el importante apartado que, con el título "De la anfibología de los conceptos de reflexión", incluye como "Apéndice" a la "Analítica trascendental", inmediatamente a continuación de la sección dedicada a la distinción crítica entre fenómenos y noúmenos, es decir, en el lugar estratégico que marca la transición a la "Dialéctica trascendental". Además del interés histórico que reviste la famosa discusión con Leibniz que Kant lleva a cabo en el pasaje, el texto de la "Anfibología" posee un interés sistemático que no siempre ha sido adecuadamente apreciado en todo su alcance, y que se conecta, fundamentalmente, con el modo en que el propio Kant da cuenta del papel que cumplen los procesos de mediación reflexiva en la formación originaria de juicios objetivos, dotados, como tales, de genuino alcance cognitivo. Si mi reconstrucción del argumento desarrollado en el texto resulta convincente, habrá que decir que el tratamiento de la noción de 'reflexión' (Überlegung, reflexio) contenido en la sección inicial de la "Anfibología" permite hacerse una idea bastante más diferenciada del complejo modelo explicativo que Kant tiene aquí en vista. Para Kant, un juicio objetivo constituye un enlace sintético de representaciones ya dadas, más precisamente, de al menos dos conceptos que ocupan, respectivamente, el lugar del sujeto y el predicado. Sobre dichos conceptos recaen, en el acto de la formación originaria del juicio, los correspondientes procesos de mediación reflexiva por vía de comparación, tanto de tipo meramente lógico como de tipo trascendental. Desde el punto de vista constitutivo, tales procesos de mediación reflexiva preceden, pues, a la introducción del enlace categorial que da origen al juicio mismo, con su correspondiente contenido judicativo. Sin embargo, en el caso de los juicios genuinamente objetivos, que involucran, como tales, no sólo la referencia a objetos de la experiencia, sino también la pretensión de validez respecto de dichos objetos, los conceptos destinados a ocupar el lugar del sujeto y del predicado deberán ser, en definitiva, conceptos empíricos. En efecto, ni las ciencias de la naturaleza ni mucho menos, por cierto, la propia actitud natural pueden limitarse a operar con meros conceptos puros, ni tampoco están en condiciones de obtener sus

cleo especulativo de la posición que intento defender, y me comunicó una serie de observaciones que me han permitido advertir nuevas conexiones sistemáticas y ampliar así la perspectiva de mi enfoque.

${ }^{1}$ Véase Vigo 2006.

Diánoia, vol. LIII, no. 61 (noviembre 2008). 
propios conceptos de modo puramente constructivo, como lo hace la matemática. $^{2}$

Ahora bien, si la disponibilidad de conceptos empíricos, que no pueden ser provistos por el propio entendimiento y deben ser obtenidos a partir de la experiencia, constituye un requerimiento previo para la posible formación originaria de juicios objetivos, la pregunta que se plantea aquí es qué puede y, eventualmente, qué debe decirse sobre la cuestión relativa a la formación de dichos conceptos, desde el punto de vista propio de la filosofía trascendental. Como es sabido, en el así llamado Logikcorpus kantiano, se encuentra material bastante abundante que da cuenta de la cuidadosa atención que Kant dedicó al problema de la formación de conceptos empíricos, sobre la base de los correspondientes procedimientos de comparación, reflexión y abstracción. Y en la investigación más reciente, la lógica kantiana de los conceptos y, en particular, los aspectos relativos al proceso de la formación originaria de conceptos empíricos, han pasado a ocupar una posición privilegiada en el interés de un buen número de intérpretes, como resultado de la toma de conciencia, cada vez más agudizada, de la importancia decisiva que poseen tales desarrollos doctrinales, cuando se trata de comprender adecuadamente el origen y el alcance de buena parte de las posiciones centrales de contenido que Kant adopta de modo expreso en el marco de su lógica trascendental. Con todo, aunque la relación entre lógica de los conceptos y lógica trascendental ha sido abordada desde

${ }^{2}$ Con esto se conecta la posición, en cierto sentido, ambivalente que Kant concede a la matemática, como una peculiar forma de conocimiento científico. Por un lado, si se atiende a su carácter riguroso y a su modo de proceder completamente independiente de la experiencia, la matemática parece proveer el ejemplo paradigmático del tipo de saber que la razón humana, al menos en su uso científicoespeculativo, ambiciona. En tal sentido, Kant mismo señala que allí donde se trata de dar cuenta de la posibilidad del conocimiento sintético a priori, la matemática parece constituir el verdadero "orgullo de la razón humana" (Stolz der menschlichen Vernunft) (cfr. KrV A 464/B 492). Por otro lado, considerada desde el punto de vista metodológico, la matemática posee un carácter meramente constructivo, en la medida en que se limita a construir sus propios conceptos y, sobre esa base, a exhibir a priori los correspondientes objetos en la intuición pura. En esa misma medida, no puede contar todavía como un genuino conocimiento de objetos, ya que, por sí sola, no posee todavía genuina referencia objetiva. Esto explica que, a juicio de Kant, ni la ciencia de la naturaleza ni tampoco, contra lo que ha sido su gran tentación a lo largo de la historia, la filosofía misma puedan ni deban querer imitar el modo de proceder propio de la matemática (cfr. A 712-738/B 740-766). Para la posición sistemática del caso de la matemática, y para el motivo de la superación del ideal matemático del conocimiento en Kant, véase la muy buena discusión de conjunto en von Wolff-Metternich 1995, esp. el cap. 2. 
diferentes ángulos, la perspectiva de análisis habitualmente practicada tiene una orientación predominantemente unidireccional, en la medida en que busca en los textos del Logikcorpus presupuestos de la concepción presentada en $\mathrm{KrV}$, con frecuencia sin preguntarse expresamente por el modo en que dicha concepción retroactúa, a su vez, sobre los elementos de lógica conceptual que quedan integrados y subordinados a ella. Formulada en términos generales, la pregunta que abre esta perspectiva de análisis complementaria es la pregunta por las condiciones apriorísticas de posibilidad de las estructuras y los procesos de formación que tematiza la lógica de los conceptos. En términos más específicos, y con referencia exclusivamente al problema particular de la formación originaria de los conceptos empíricos, la pregunta que aquí interesa sería, pues, la de si hay determinados principios a priori que intervienen en dicho proceso, haciéndolo, como tal, posible. De ser así, dicho proceso formaría, al menos en lo que concierne al papel de los principios que lo posibilitan, parte del ámbito de competencia de la filosofía trascendental. Una segunda pregunta más específica, que supone una respuesta positiva a la anterior, concierne al tipo de función que cumplen tales principios en el proceso de formación de conceptos empíricos, a saber: ¿se trata de una función constitutiva o meramente heurístico-regulativa?, ¿tiene lugar de modo determinante o, más bien, de modo reflexivo?

Es en el contexto señalizado por estas preguntas, y en conexión directa con la temática abordada por Kant en el tratamiento de los conceptos de reflexión, donde la referencia a un escueto y oscuro texto de la segunda edición de $K r V$, el $\S 12$ de la "Analítica de los conceptos", adquiere una relevancia sistemática, a primera vista, insospechada. ${ }^{3} \mathrm{El}$ $\S 12$, ubicado en el lugar de transición entre la deducción metafísica y la deducción trascendental de las categorías, constituye un añadido a la segunda edición de $\mathrm{KrV}$, en el cual Kant intenta integrar en su propia filosofía crítica la temática de los así llamados "trascendentales", tal

${ }^{3}$ En virtud de su oscuridad, el $\S 12$ no ha recibido, en general, la atención que merece. La conexión sistemática con el tratamiento de los conceptos de reflexión que Kant lleva a cabo en la "Anfibología" ha pasado, por lo mismo, poco menos que inadvertida. Una notable excepción se encuentra ahora en la interpretación desarrollada por Natterer 2003, esp. pp. 344-379. Para una concisa e ilustrativa discusión de algunos de los principales aspectos sistemáticos de la posición que Kant elabora en el $\S 12$, también con referencia a textos relevantes del Logikcorpus y el Nachlaß, véase también Baumanns 1997, pp. 251-265. Material todavía valioso para la reconstrucción del desarrollo histórico que lleva de la doctrina tradicional de los trascendentales hasta Kant se encuentra en Bärthlein 1976.

Diánoia, vol. LIII, no. 61 (noviembre 2008). 
como ésta había caracterizado a la metafísica tradicional. Como es sabido, en el caso de los trascendentales se trata, según la doctrina tradicional, de aquellos predicados que, por ser coextensivos con 'ser', poseen un carácter "transgenérico" o, más precisamente, "transcategorial". En efecto, así como 'ser' no designa un supuesto "género", que estuviera situado por encima de los géneros supremos de todo lo que es, provistos por las así llamadas "categorías", tampoco predicados como 'uno', 'verdadero' y ‘bueno' podrían designar "géneros" de cosas, en el sentido estricto del término, y ello ya por la sencilla razón de que se predican con tanta amplitud como 'ser'. En virtud de tal coextensividad con 'ser', dichos predicados recibieron, pues, el nombre de "trascendentales", que alude al hecho de que su aplicación se extiende más allá del ámbito demarcado por cada una de las categorías. Pues bien, la circunstancia de que en el caso del $\S 12$ se trata de un añadido de alcance aparentemente ocasional, unida a la brevedad y la dificultad del texto, llevó a connotados intérpretes a ver aquí una suerte de tributo de Kant a los requerimientos de la unidad arquitectónica —en este caso, avalados, además, por una tradición venerable-, que no cumpliría, sin embargo, ningún papel sustantivo dentro de la teoría de la constitución de la experiencia y la posibilidad del conocimiento desarrollada en la obra. ${ }^{4}$ A lo sumo, se trataría de un intento por mostrar que la filosofía crítica permite incorporar no sólo la temática propia de la doctrina tradicional de las categorías, sino también, de algún modo, la temática propia de la doctrina tradicional de los trascendentales.

Ocurre, sin embargo, que la problemática presentada en el $\S 12$, de modo tan apretado y, a juzgar por el escaso eco positivo suscitado, tan poco atractivo, viene precedida por una larga y compleja historia, tanto en las Reflexionen como en las lecciones de metafísica, sobre todo, las de la época crítica, donde Kant lleva a cabo varios intentos diferentes de asimilación de la doctrina tradicional de los trascendentales. ${ }^{5} \mathrm{Y}$, en

${ }^{4}$ Así, especialmente, Kemp Smith 1923, p. 200: "This section, of no intrinsic importance, is an example of Kant's loving devotion to this 'architectonic'. His reasoning is extremely artificial, especially in its attempt to conect 'unity, truth and perfection' with the three categories of quantity" ["Esta sección, carente de importancia intrínseca, es un ejemplo de la devoción amorosa de Kant a esta 'arquitectónica'. $\mathrm{Su}$ razonamiento es extremadamente artificial, especialmente en su intento de conectar 'unidad, verdad y perfección' con las tres categorías de cantidad"].

${ }^{5}$ Véanse esp. Reflexionen, 5243-5248 (= XVIII 129-131); 5733-5749 (XVIII 339-343); Metaphysik Dohna, pp. 631 s.; Metaphysik L2, pp. 555 s.; Metaphysik Schön, pp. 495 ss.; Metaphysik Volckmann, pp. 414 ss., 421. No se sabe con certeza de qué fuentes Kant tomó la peculiar versión de la doctrina de los trascendentales en la que basa su intento de reinterpretación. Baumanns 1997, pp. 251 s., mencio- 
rigor, ya el solo hecho de que Kant haya tomado la decisión de incluir el § 12 con ocasión de la preparación de la segunda edición, y de colocarlo inmediatamente antes de la versión completamente renovada de la "Deducción trascendental de las categorías" (DTB), contenida en los $\S \S 13-27$, sugiere, más bien, que no puede tratarse aquí de un añadido carente de relevancia sistemática. Esta suposición se ve avalada, además, por el hecho de que ya en pleno desarrollo del argumento de DTB, más concretamente, en el $\S 15$, dedicado a la caracterización de la fundamental noción de 'enlace' (Verbindung), Kant introduce una referencia expresa a la concepción presentada en el § 12, más concretamente, a la noción de 'unidad cualitativa' (qualitative Einheit), que Kant cree haber logrado obtener a partir de su reinterpretación del significado del trascendental unum, y que distingue expresamente de la categoría de unidad (Kategorie der Einheit) presentada previamente en el $\S 10$ (cfr. B 131). ${ }^{6}$

Desde luego, resulta razonable suponer que, al menos en parte, el interés de Kant por llevar a cabo una incorporación asimiladora de la doctrina tradicional de los trascendentales en su propia filosofía crítica se relaciona con la importancia histórica de dicha doctrina. Por otra parte, podría sospecharse que también la intención de salir al paso de la objeción de una simple y llana omisión, que pondría indirectamente

na la Metaphysik de Clemens Timpler (1604) y el Systema metaphysicum de Johann Peter Reusch (1735), obras que presentan variantes de dicha doctrina "escolástica”. En el mismo sentido, Knittermeyer 1920, p. 196, citado por Baumanns, había remitido a las Institutiones Metaphysicae de Friedrich Christian Baumeister (1733, 1774), texto que Kant empleó como base de su lección de metafísica dictada en el año académico 1756/1757.

${ }^{6}$ Para ilustrar el drástico cambio en el estado de la cuestión relativa a la relevancia sistemática de la discusión de los trascendentales en el § 12 que ha producido la investigación más reciente, vale la pena citar el veredicto de Natterer 2003, p. 344, quien señala: "Die endgültige Fassung dieser von Kant als erstrangig wichtig und selbstverständlich erachteten begriffslogischen Metatheorie findet sich im § 12 der Deduktion B. Die Metaphysikvorlesungen der kritischen Epoche belegen, dass Kant diese begriffslogische Transzendentalientheorie stets rezipiert und integriert hat, und der o.g. § 12 der Kritik diese im kantischen Denken systematisch und diachronisch fest etablierte Transzendentalientheorie lediglich kompakt zusammenfasst" ["La versión definitiva de esta metateoría de lógica conceptual, que Kant consideraba dotada de una importancia de primer rango y obvia, se encuentra en el $\S 12$ de la Deducción B. Las Lecciones de metafísica de la época crítica prueban que Kant recibió e integró constantemente esta teoría de los trascendentales, vinculada a la lógica de los conceptos, y el citado $\S 12$ de la Crítica simplemente resume de modo compacto esta teoría de los trascendentales, que está firmemente establecida, desde el punto de vista sistemático y diacrónico, en el pensamiento de Kant"].

Diánoia, vol. LIII, no. 61 (noviembre 2008). 
en cuestión el carácter cerrado y completo del sistema de las categorías, pudiera haber desempeñado algún tipo de papel desencadenante, en la decisión de incorporar el texto del $\S 12$ en la segunda edición de $\mathrm{KrV}$. Sin embargo, nada de esto excluye por sí mismo, sino que, más bien, presupone la convicción de parte de Kant de que la doctrina que busca integrar y asimilar documenta un conjunto de intuiciones elementales que, más allá de lo que pudieran ser las insuficiencias del enfoque propio de la metafísica tradicional, poseen un importante núcleo de verdad y, por tanto, deben ser retenidas, con las debidas modificaciones. Por lo demás, nada exime tampoco de la tarea de explicar en detalle el modo en que Kant lleva a cabo la recontextualización que tiene aquí en vista. En definitiva, se trata, pues, de establecer cuál es la función específica que Kant asigna a los tres conceptos tematizados en el $\S 12$, y ello, dado el peculiar marco sistemático de tratamiento que he esbozado al comienzo, con especial atención al problema que plantea la pregunta por los principios a priori que intervienen en el proceso de formación originaria de conceptos empíricos.

A los fines que aquí interesan, hay que considerar, pues, sobre todo, los siguientes aspectos fundamentales, a saber: en primer lugar, la vinculación existente entre los conceptos, en general, la función fundamental del enlace de representaciones y los modos correspondientes de la unidad de conciencia (secciones 2 y 3); y, a continuación, el aporte efectivo que, según Kant, corresponde a los conceptos trascendentales - como requerimientos lógicos de todo conocimiento de objetos y, con ello, más específicamente, como principios regulativos de la formación de conceptos empíricos-, en relación con la posibilidad del conocimiento de objetos (sección 4). Hecho esto, a modo de conclusión, habrá que retornar, por último, muy brevemente a la cuestión general de la vinculación existente entre la temática de los trascendentales, por un lado, y la temática relativa al papel posibilitante que cumplen los procesos de mediación reflexiva, respecto de los actos de determinación dotados de genuina referencia objetiva y, con ello, de verdadero alcance cognitivo, por el otro (sección 5). La discusión permitirá advertir mejor, así lo espero, en qué medida la concepción elaborada en el $\S 12$ de la "Analítica de los conceptos" da testimonio, desde el punto de vista sistemático, de la misma orientación básica que la presentada en la "Anfibología". 


\section{Conceptos, categorías y enlace de representaciones}

A los efectos de comprender mejor la posición elaborada por Kant, conviene partir de la ya mencionada observación del § 15 de DTB, que opone dos formas diferentes de unidad: una categorial, de carácter cuantitativo, y otra supra- o transcategorial, de carácter cualitativo. Kant explica allí que el concepto de 'enlace' (Verbindung) involucra necesariamente tres aspectos, a saber: 1) una multiplicidad (das Mannigfaltige) a ser enlazada, 2) la síntesis (Synthese) de tal multiplicidad y, además, 3) la unidad (Einheit) de la multiplicidad sintetizada (cfr. B 130). En tal sentido, y retomando expresamente los tres aspectos mencionados, Kant define al enlace, en general, como "la representación de la unidad sintética de lo múltiple" (die Vorstellung der synthetischen Einheit des Mannigfaltigen) (cfr. B 130). Mientras que el aspecto 1) corresponde, en general, al aporte de la intuición sensible, como facultad receptiva (cfr. B 129), los aspectos 2) y 3), que son indispensables para que tenga lugar el enlace, remiten, en cambio, a representaciones que no pueden tener su origen en la intuición, sino que poseen un carácter irreductiblemente intelectual o conceptual. Por tal motivo, Kant enfatiza el hecho de que la representación de un enlace, no importa de qué tipo sea, no puede sernos dada jamás a través de los sentidos, de modo puramente pasivo-receptivo (cfr. B 129-130), sino que remite siempre en su origen a un acto espontáneo de la facultad de representación (ein Actus der Spontaneität der Vorstellungskraft) o, lo que es lo mismo, a un acto que, como tal, da cuenta de la capacidad de autoactivación (Selbsttätigkeit) propia del sujeto ( $c f r$. B 130). Esto tiene, como es sabido, consecuencias decisivas para el curso posterior del argumento desarrollado en DTB. Ahora bien, aunque tanto 2) como 3) remiten al ámbito de las representaciones conceptuales, no se trata en ambos casos del mismo tipo de representación, sino de representaciones diferentes, que cumplen dentro del enlace una función también diferente. Kant aclara este punto central para su posición, llamando la atención sobre el hecho de que el aporte correspondiente a 3) es específico, y no puede ser reducido, como tal, al aporte propio de 2). En efecto, Kant explica que la unidad que el enlace trae necesariamente consigo, en todas sus posibles modalidades de realización efectiva, precede ella misma a priori a todo posible concepto específico de enlace, lo cual implica que dicha unidad no puede identificarse, como tal, con ninguna forma peculiar de enlace sintético, tampoco con la que corresponde a la categoría de unidad (cfr. B 131). Se trata, más bien, como se verá, de una unidad de carácter cualitativo, que está, como tal, presente incluso allí donde no se tiene 
todavía el tipo peculiar de enlace judicativo que facilitan las categorías. Todas las categorías constituyen reglas de enlace basadas en las funciones lógicas de los juicios. Pero los juicios, justamente en la medida en que enlazan sintéticamente diferentes conceptos, presuponen siempre ya un previo enlace (Verbindung), puesto que presuponen la unidad de los conceptos vinculados, los cuales tienen que estar ya dados (Einheit gegebener Begriffe). En tal sentido, explica Kant, en su función específica de enlace para dar lugar al juicio, la categoría presupone siempre ya un previo enlace de representaciones (cfr. B 131).

Esta constatación puede parecer, a primera vista, sorprendente, si no se tiene en cuenta que, ya desde un comienzo, Kant llama la atención sobre el hecho de que si bien el enlace es, como tal, siempre una obra del entendimiento (eine Verstandeshandlung), no se sigue de ello que todo enlace posea la misma estructura, ni quede referido al mismo tipo de representaciones. Por el contrario, en algunos casos, la unidad sintética de carácter representacional que produce el acto de enlace se refiere de modo directo a la multiplicidad dada en la intuición (eine Verbindung des Mannigfaltigen der Anschauung), mientras que, en otros casos, queda referida, más bien, a determinados conceptos (mancherlei Begriffe) (cfr. B 130). ${ }^{7}$ Ahora bien, parece suficientemente claro, a

${ }^{7}$ Una complicación adicional viene dada por el hecho de que, en el caso de la intuición, Kant remite a la alternativa entre una intuición "sensible" (sinnliche) y una "no sensible" (nicht sinnliche Anschauung) (cfr. B 130). Pero está claro que bajo 'intuición no sensible' Kant no puede tener en vista aquí el caso de una intuición intelectual, en el sentido preciso en que ésta pertenecería a un intelecto originario que diera realidad a su objeto con sólo pensarlo, ya que dicho intelecto tampoco tendría nada que enlazar sintéticamente (cfr. A 256-257/B 311-312). Probablemente siguiendo a Mellin, Paton (1936, I, p. 504 n. 3) sugiere que el pasaje contiene una simple confusión terminológica: Kant tendría en mente, en realidad, la oposición entre intuición "empírica" y "no empírica", y no entre intuición "sensible" y "no sensible". Más adecuada parece, sin embargo, la posición de Baum 1986, pp. 85 s., quien enfatiza el hecho de que 'sensible' e 'intelectual' no son determinaciones contradictorias, sino sólo contrarias, lo cual permite entender la referencia de Kant a una intuicion "no sensible" como una alusión a un modo indeterminado de intuición que, sin ser intelectual, tampoco se corresponde con el modo de intuición propio del hombre, que es el único al que Kant denomina propiamente como "intuición sensible" (cfr., p.ej., DTB § 23). El contraste entre la intuición sensible propia del hombre, por un lado, y la representación indeterminada de una intuición que, sin ser intelectual, tampoco tuviera el carácter específico (espacio-temporal) de nuestra intuición sensible, por el otro, da lugar a la importante distinción entre una síntesis "figurada" (figürliche Synthese, syntesis speciosa) y una síntesis puramente "intelectual" (Verstandesverbindung, synthesis intellectualis), donde ésta última, como lo muestra ya el mero empleo de la noción de 'síntesis', no corresponde al 
la luz de lo ya dicho sobre el carácter no autosustentado del enlace categorial, en el proceso de formación originaria de juicios objetivos, que no hay que ver en las dos posibles formas de enlace aquí aludidas una simple alternativa entre diferentes especies, situadas, como tales, al mismo nivel. Más bien, hay que decir que ambas formas de enlace se corresponden con dos niveles diferentes de actividad sintética, comprendidos dentro de un modelo estratificado de constitución. En efecto, se tiene, por un lado, el tipo de enlace que permite reunir una multiplicidad intuitivamente dada bajo la unidad de un concepto, y, por otro, el enlace entre conceptos ya dados, tal como éste es posibilitado por las categorías, como tales. Desde el punto de vista del modelo estratificado de constitución que pretende dar cuenta de la génesis y la estructura del tipo de acceso cognitivo a objetos que posibilitan los juicios objetivos, los dos modos de enlace mencionados constituyen, puede decirse, el terminus a quo y el terminus ad quem, respectivamente, de la explicación ensayada por Kant. A ellos se añade, situado en una posición intermedia, un tercer nivel, que comprende aquellas formas de enlace judicativo, carentes por sí mismas de genuino alcance cognitivo, en las cuales la función judicativa que enlaza representaciones en la conciencia no aparece, como tal, dotada de (pretensión de) validez objetiva. ${ }^{8}$

La unidad cualitativa que, como se verá a continuación, constituye un requerimiento lógico que debe ser satisfecho por todo conocimien-

caso de la intuición intelectual, sino, más bien, a la representación indeterminada del enlace sintético, por medio de categorías, de una multiplicidad dada por medio de una intuición X (in Ansehung des Mannigfaltigen einer Anschauung überhaupt) (cfr. DTB \& 24, esp. B 151).

${ }^{8}$ Dentro del ámbito de los enlaces que, en general, pueden denominarse de carácter no categorial, conviene distinguir, a los efectos que aquí interesan, dos tipos diferentes, a saber: por una parte, aquellos que, sin proveer ellos mismos conocimiento de objetos, están, por así decir, ordenados a él, en la medida en que entran a formar parte, como elementos constitutivos, de la síntesis judicativa que da lugar a un juicio objetivo; por otra parte, aquellos otros que no están, como tales, ordenados a ningún tipo de conocimiento. Ejemplos del primer tipo son los conceptos empíricos y también, de un modo diferente, el peculiar tipo de enlace (pre)judicativo, de alcance puramente subjetivo, que Kant tematiza, desde diferentes ángulos, tanto en el tratamiento de la noción de reflexión lógica de la "Anfibología", como en el tratamiento del así llamado "juicio de percepción" (Wahrnehmungsurteil), por oposición al "juicio de experiencia" (Erfahrungsurteil), en Prolegomena §§ 18-21 (para mayor detalle sobre el alcance de este tipo de casos, desde el punto de vista de la concepción kantiana de la reflexión como presupuesto del juicio, véase Vigo 2006, pp. 33 ss.). Como ejemplo del segundo tipo de enlace no categorial, se puede mencionar, en cambio, el caso del "juicio puro de gusto" (reines Geschmacksurteil) (véase la nota siguiente).

Diánoia, vol. LIII, no. 61 (noviembre 2008). 
to, ha de estar presente, como tal, en todo tipo de enlace sintético de representaciones. Esto implica, desde el punto de vista que aquí interesa, una doble consecuencia, a saber: por una parte, que todo enlace sintético de carácter categorial, tal como éste tiene lugar en un juicio objetivo, puede contar como ejemplo, al mismo tiempo, del tipo de unidad cualitativa que es propio de todo conocimiento; y, por otra parte, que tiene que haber unidad cualitativa incluso allí donde se está en presencia de un enlace sintético de representaciones que, sin poseer él mismo naturaleza categorial ni poder proveer por sí solo conocimiento de objetos, constituye, a la vez, un elemento que entra a formar parte necesariamente de los enlaces categoriales, como es el caso del tipo de enlace que corresponde a los conceptos empíricos que entran a formar parte de los juicios objetivos. Consideremos ahora, un poco más de cerca, este último aspecto.

\section{Conceptos como reglas de enlace. La función de unificación de los conceptos empíricos y la unidad de la conciencia}

Los juicios objetivos, dotados, como tales, de genuino alcance cognitivo, presuponen la intervención de un enlace categorial que permite vincular, con pretensión de validez objetiva, los conceptos que ocupan, en cada caso, el lugar del sujeto y el predicado del juicio. Ésta es una tesis cuya adscripción a Kant nadie querría poner seriamente en duda. En cambio, menos evidente podría resultar, al menos a primera vista, que la otra forma de enlace a la que Kant alude en el texto comentado se corresponda efectivamente con la función de unificación que desempeñan respecto de las correspondientes intuiciones los conceptos que proveen la materia de los juicios de la forma S-P. Pero, como se dijo ya, el propio Kant establece en el pasaje antes citado que la síntesis que provee la base para la intervención del enlace categorial concierne a la unidad de conceptos dados. Que este último punto no constituye una consideración aislada puede mostrarse apelando a otros pasajes, en los cuales Kant caracteriza de modo específico la función de unificación de representaciones que cumplen los conceptos, en general, y los conceptos empíricos que proveen la materia de los juicios objetivos, en particular.

Como es sabido, en $\mathrm{KrV}$ Kant caracteriza a todos los juicios, en el sentido estrecho que remite a los juicios objetivos dotados de alcance cognitivo, ${ }^{9}$ como ciertos tipos de funciones de unidad (Funktionen der

${ }^{9}$ No hace falta abundar demasiado en el hecho de que Kant utiliza la noción de juicio (Urteil) de diferentes modos en diferentes contextos, y que admite incluso 
Einheit) de representaciones (Vorstellungen), que hacen posible el conocimiento del correspondiente objeto (Erkenntnis des Gegenstandes) al que dichos juicios, como tales, se refieren. Desde el punto de vista de su estructura interna, lo propio del enlace judicativo consiste en que un concepto (Begriff), que, como tal, comprende en sí otras representaciones, queda referido por medio de alguna de ellas a un determinado objeto. En atención a su función más específica de unificación de representaciones, el concepto puede ser caracterizado, en general, como aquel tipo de representación que provee el predicado para un posible juicio (cfr. A 69/B 94). Pero dentro de la estructura del juicio, tal como éste se realiza en concreto, hay que distinguir entre la función del concepto que oficia de sujeto y la del que oficia de predicado. Así, explica Kant, en todo juicio de la forma S-P, aparece, del lado del predicado, un concepto que "es válido" (gilt) respecto de muchas representaciones, entre las cuales hay una, la que aparece del lado del sujeto, que queda referida de modo inmediato (unmittelbar) al objeto correspondiente. Por ejemplo, en el juicio 'todos los cuerpos son divisibles', el concepto de 'divisible', que, como tal, puede ser predicado de una multiplicidad de otras representaciones, queda referido al concepto de 'cuerpo', el cual se refiere, a su vez, a determinados fenómenos (Erscheinungen) de los que tenemos experiencia de modo inmediato, esto es, a los objetos corpóreos que se ofrecen en la percepción (cfr. A 68/B 93). ${ }^{10}$ Atendiendo

la existencia de juicios que no enlazan conceptos, sino representaciones de diverso tipo. Un caso notorio es el del "juicio puro de gusto" (reines Geschmacksurteil), tal como aparece caracterizado en $K U$, el cual, en su forma más pura —correspondiente al caso de la "belleza libre" (freie Schönheit, pulchritudo vaga), por oposición a la así llamada "belleza adherente" (anhängende Schönheit, pulchritudo adhaerens)— vincula de modo inmediato, esto es, sin concepto del objeto, la representación del objeto intuitivamente dado en la percepción, que constituye a la vez el sujeto del juicio, con el sentimiento (Gefühl) de placer que dicha representación intuitiva produce en la reflexión desinteresada, sentimiento que provee, entonces, él mismo, y no su concepto, el predicado del juicio (para este punto, veáse la excelente reconstrucción en Wieland 2001, pp. 185-221). Para hacer lugar a aquellos juicios que enlazan representaciones de carácter no conceptual, Kant introduce en KU la noción de "juicio estético" (ästhetisches Urteil), por oposición al "juicio lógico" (logisches Urteil) o "juicio cognitivo" (Erkenntnisurteil) (cfr. KU § 1) (para la concepción kantiana en torno a los juicios de carácter no conceptual, véase Wieland 2001, pp. 78-103). Como acertadamente hace ver Stuhlmann-Laeisz 1976, pp. 55-59, en las lecciones de lógica Kant opera con definiciones relativamente amplias de la noción de juicio, bajo las cuales se incluyen algunos tipos de enlaces judicativos que no satisfacen las exigencias que plantea el modo más estricto en el que se caracteriza la noción, en el contexto específico de la lógica trascendental.

${ }^{10}$ Para una interpretación en esta misma línea, que enfatiza la función referen-

Diánoia, vol. LIII, no. 61 (noviembre 2008). 
al hecho de que en el enlace judicativo los fenómenos en cuestión son conocidos siempre a través del concepto contenido en el predicado, que se añade sintéticamente al concepto contenido en el sujeto, Kant puede caracterizar formalmente al juicio como "el conocimiento mediato de un objeto" (die mittelbare Erkenntnis eines Gegenstandes) o, lo que es lo mismo, como "la representación de una representación" (die Vorstellung einer Vorstellung) de dicho objeto (cfr. A 68/B 93).

Según esto, desde el punto de vista concerniente a la función de unificación que desempeñan los conceptos que proveen su materia, habría que decir que la estructura del juicio presenta una suerte de doble relación de determinación, a saber: por un lado, 1) del predicado respecto del sujeto, y, por el otro, 2) del sujeto respecto del objeto. Pero se trata aquí de dos relaciones de alcance completamente diferente. En efecto, mientras que 1) constituye una relación entre conceptos, 2) debe verse, en cambio, como la relación de un concepto respecto de lo que es dado en la intuición, es decir, respecto de aquello que ya no es ni puede ser de naturaleza meramente conceptual. La diferencia estriba aquí, básicamente, en el hecho de que el juicio constituye una función de unidad sintética de representaciones conceptuales, mientras que, considerado por sí mismo, es decir, sin atender a su función predicativa dentro del juicio, el concepto aparece, más bien, como aquella función de unidad sintética que permite reunir una multiplicidad de representaciones intuitivas particulares bajo una misma y única representación universal, que oficia, a su vez, de regla para dicha reunión unificadora (cfr. A 103). ${ }^{11}$ En tal sentido, Kant explica que un concepto es siempre una representación universal, bajo lo cual hay que entender, en definitiva, una representación de lo que es común a diferentes objetos, la cual se refiere a dichos objetos, precisamente, a través de esa "característica" o "nota" (Merkmal) compartida (cfr. A 320/B 377; véase Jäsche Logik $\S 1$, p. 9, n. 1). ${ }^{12}$ El concepto constituye, en tal sentido, una suerte de

cial básica que desempeña el concepto sujeto del juicio, véase Longuenesse 1998b, pp. 140 ss. y 2005a, pp. 91 ss. De modo semejante, también Wolff 1995, pp. 80 s. Una crítica parcial a este tipo de interpretación, que, a mi juicio, no resulta suficientemente convincente, se encuentra en Prien 2006, pp. 31 ss.

${ }^{11}$ Para la caracterización del concepto por referencia a la función de unidad sintética, véase también A 68/B 93: "Alle Anschauungen, als sinnlich, beruhen auf Affektionen, die Begriffe also [Adickes: "aber"] auf Funktionen. Ich verstehe aber unter Funktion die Einheit einer Handlung, verschiedene Vorstellungen unter einer gemeinschaftlichen zu ordnen".

${ }^{12}$ La distinción entre 'concepto' (Begriff) y 'nota' (Merkmal) desempeña un papel central en la teoría del concepto que Kant elabora en el Logikcorpus (véase esp. Reflexionen 2275-2288; Jäsche Logik, "Einleitung" VIII, p. 58; Logik Blomberg 
regla de las intuiciones (Regel der Anschauungen) (cfr. A 106). ${ }^{13}$ Aunque Kant no es demasiado explícito al respecto, parece claro que, al menos en el caso de los conceptos empíricos que proveen la materia de los juicios objetivos, hay que hacer lugar aquí a dos tipos diferentes de función de referencia unificadora, a saber: por un lado, la que permite reconducir, de modo directo o inmediato, una multiplicidad dada (o

$\S \S 115-123,261)$. Las notas son consideradas como los únicos medios a través de los cuales conocemos las cosas y, en tal sentido, como fundamentos de conocimiento (Erkenntnisgründe) (cfr. Reflexionen 2281, 2286; Jäsche Logik, "Einleitung" VIII, p. 58). La nota es, como tal, una representación parcial (Reflexionen 2286: Theilvorstellung; Jäsche Logik: Partialvorstellung), y puede ser de carácter intuitivo (intuitiv), esto es, una parte de la intuición (ein Theil der Anschauung), o bien de carácter discursivo (diskursiv), es decir, una parte de un concepto (ein Theil des Begriffs). A la del primer tipo Kant la denomina una "parte sintética" (synthetischer Theil), a la del segundo tipo, una "parte analítica" (analytischer Theil), en la medida en que la una y la otra operan como fundamento del conocimiento sintético y del conocimiento analítico, respectivamente (cfr. Reflexionen 2286). Como se echa de ver, en cuanto forma parte de la comprensión de otros conceptos, todo concepto es también una nota, más precisamente, una nota discursiva, pero, inversamente, no toda nota es un concepto, ya que hay también notas de carácter intuitivo. La distinción entre 'nota discursiva' y 'concepto' tiene, pues, un alcance funcional y contextual, no así la distinción entre 'nota intuitiva' y 'nota discursiva', que remite, en definitiva, a la diferencia irreductible entre las dos fuentes últimas de las que procede todo conocimiento: la intuición y el entendimiento. A la relación entre los conceptos y las intuiciones apunta, como puede advertirse, la caracterización kantiana de los conceptos como reglas que permiten la unificación de múltiples representaciones intuitivas. Por lo mismo, y especialmente, en el caso de los conceptos empíricos (para el caso de los conceptos puros, véase la nota siguiente), tal caracterización debe entenderse en sentido puramente referencial-extensional, y no como si quisiera significar que las intuiciones unificadas en cada caso pasaran a formar parte del contenido intensional de los conceptos que las unifican. Para una útil discusión sintética de la concepción kantiana de la relación entre notas y conceptos, véase Stuhlmann-Laeisz 1976, cap. 5; véase también Prien 2006, pp. 58-67. Para una reconstrucción de conjunto del uso kantiano de la noción de 'nota', véase Capozzi 2002, pp. 484-499.

${ }^{13}$ Esta caracterización del concepto como una función de unidad sintética de representaciones intuitivas resulta, como tal, todavía neutral respecto de la ulterior distinción entre conceptos empíricos y conceptos puros, ya que se aplica, de modo analógico, tanto a unos como a otros: mientras que los conceptos empíricos permiten reconducir a la unidad de una representación universal una multiplicidad de representaciones intuitivas dadas en la percepción, de un modo análogo los conceptos puros proveen reglas de síntesis para la unificación de la multiplicidad dada $a$ priori en las representaciones intuitivas del espacio y el tiempo, que, como se sabe, constituyen las formas puras de la intuición sensible. La posibilidad de unificación conceptual de la multiplicidad intuitiva dada a priori en el espacio y el tiempo posee, como tal, una importancia sistemática fundamental, no sólo allí donde se

Diánoia, vol. LIII, no. 61 (noviembre 2008). 
dable) intuitivamente a la unidad de un concepto, tal como ocurre en el caso del concepto sujeto de un juicio (universal o particular); por otro, la función indirecta de unificación que corresponde al concepto predicado del juicio, en la medida en que, vinculado al sujeto, incluye a éste en una clase (generalmente) más amplia de objetos. En ambos casos puede decirse con razón que el concepto opera como una regla de las intuiciones, aunque lo hace, en uno y otro caso, en diferentes niveles de constitución, como lo muestra ya el hecho de que la función de unificación desempeñada por el concepto predicado se sitúa, como tal, en el plano de las relaciones conceptuales. ${ }^{14}$

trata de dar cuenta de la posibilidad de los juicios sintéticos a priori en el ámbito del conocimiento matemático (cfr. p.ej. B 14-17; A 713-738/B 741-766), sino también allí donde se procura dar cuenta del modo en que las categorías determinan trascendentalmente la forma pura del tiempo, en términos del procedimiento denominado el esquematismo de los conceptos puros del entendimiento (cfr. A 137147/B 176-187; véase también B 151-152). Se trata en este caso, sin embargo, de un tipo completamente peculiar de función de unificación, que, especialmente, en el nivel de constitución tematizado en la doctrina del esquematismo, da cuenta de la producción originaria de configuraciones representacionales que poseen un carácter híbrido, a la vez, conceptual y sensible, como son los esquemas. Aplicada de modo analógico tanto al caso de los conceptos empíricos como al caso de los conceptos puros, la caracterización de los conceptos en términos de funciones de unidad sintética de una multiplicidad intuitivamente dada, bajo una regla universal, posee, como se puede ver, una notable amplitud, que explica también el hecho de que, en más de una ocasión, Kant pueda caracterizar al entendimiento mismo, en cuanto facultad que hace posible toda forma de mediación conceptual, como la "facultad de las reglas" (Vermögen der Regel) (cfr. A 132/B 171; A 158/B 197) o, de modo más preciso, como la "facultad de la unidad de los fenómenos por medio de reglas" (Vermögen der Einheit der Erscheinungen vermittelst der Regel) (cfr. A 302/B 359).

${ }^{14}$ Conviene aclarar que la constatación según la cual la función unificadora desempeñada por el concepto predicado se sitúa, como tal, en el plano de las relaciones conceptuales no resulta en absoluto incompatible con el reconocimiento de la existencia de una función referencial-identificatoria propia de dicho concepto, que éste cumple, al menos de modo indirecto, en la medida en que lo hace apoyándose en la función referencial-identificatoria propia del concepto sujeto. Así, en un juicio del tipo 'el gato es blanco', el concepto 'blanco', a la vez que incluye al objeto particular identificado por medio del concepto 'gato' en la clase de los objetos blancos, remite también, a través del concepto sujeto, a una determinación presente en el correspondiente objeto particular, dado actual o potencialmente en la percepción. La función referencial-identificatoria indirecta que desempeña el concepto predicado se apoya, pues, en la función referencial-identificatoria que cumple de modo directo el concepto sujeto, pero pone también en juego las relaciones lógicas, de caracter intensional y extensional, que mantienen entre sí ambos conceptos. Para el modo en que Kant trata en el Logikcorpus la comparación entre conceptos, tanto 
La función de unificación propia del concepto, a la que Kant apunta con la caracterización general de éste como una regla de las intuiciones, se da, pues, de un modo peculiar en el caso de los conceptos empíricos, en la medida en que éstos quedan referidos, de diversos modos, a una multiplicidad intuitiva empíricamente dada, mientras que los conceptos puros, en cambio, sólo adquieren referencia a los objetos de la experiencia de modo mediato, esto es, a través de la determinación trascendental de la multiplicidad intuitiva que proveen a priori las intuiciones puras de espacio y tiempo (cfr. DTB § 24). A esto se añade, además, una segunda característica de los conceptos empíricos, que los distingue de los conceptos puros: mientras que estos últimos constituyen reglas de enlace que se corresponden, en cada caso, con la forma del juicio (v.gr., según su cantidad, cualidad, relación y modalidad), los conceptos empíricos, que proveen la materia de los juicios objetivos, deben ser considerados, en atención a su peculiar función de unificación de representaciones, como aquellas reglas de enlace (de las intuiciones empíricas) que hacen posible la disponibilidad de los elementos de contenido que, en cada caso, entrarán a formar parte de los juicios objetivos, para ser enlazados por medio de las correspondientes reglas de enlace (categorías). Ahora bien, si todo enlace, como producto del entendimiento, da cuenta, al mismo tiempo, de un posible modo de la unidad de la conciencia, la pregunta que debe hacerse aquí es la referida al modo en que Kant conecta las diferentes posibles formas de enlace por medio de conceptos, puros o empíricos, con las diferentes posibles formas de la unidad de la conciencia y, de modo más específico, la referida al tipo particular de unidad de conciencia que aparece correlacionado con el peculiar modo de enlace que corresponde a los conceptos empíricos.

En el caso de los conceptos puros, como es sabido, Kant desarrolla en los $\S \S 18-21$ de DTB un argumento específico destinado a mostrar que es precisamente su intervención como reglas de síntesis lo que hace posible el tipo de peculiar unidad que el propio Kant denomina la "unidad objetiva" (objektive Einheit) de la autoconciencia (Selbstbewußtsein). La posición de Kant se basa en la idea fundamental de que la "unidad objetiva" de la conciencia sólo es posible por medio de las funciones lógicas del juicio, las cuales, empleadas como reglas para la determinación de la multiplicidad intuitivamente dada, se identifican con las categorías (cfr. DTB § 20; véanse también A 78-79/B 104-105; B 128129). Bajo "unidad objetiva" de la conciencia Kant entiende aquel tipo desde el punto de vista intensional como extensional, véase la buena presentación sintética en Prien 2006, pp. 75-89.

Diánoia, vol. LIII, no. 61 (noviembre 2008). 
de unidad de representaciones dadas (Einheit gegebener Vorstellungen) cuyo enlace, que en el enunciado que articula un juicio objetivo queda expresado por la cópula 'es', aparece dotado de la correspondiente (pretensión de) "validez objetiva" (objektiv gültig), a diferencia de lo que ocurre en el caso del enlace propio de la mera "unidad subjetiva" (subjetive Einheit) de la conciencia (por ejemplo, por medio de leyes psicológicas de asociación), el cual posee tan sólo "validez subjetiva" (subjektive Gültigkeit) (cfr. DTB § 19). La posición así elaborada no está exenta de ambigüedades, sobre todo en lo que concierne al genuino alcance que debe otorgarse a la conexión entre las nociones de 'enlace categorial' y 'unidad objetiva de la conciencia'. En efecto, hay buenas razones para pensar que, desde el punto de vista sistemático, no basta la referencia general a la intervención de enlace categorial para dar cuenta de la presencia del tipo de (pretensión de) validez objetiva que Kant tiene en vista cuando se refiere a la unidad objetiva de la conciencia. Más bien, como sugieren los propios ejemplos a partir de los cuales se orienta Kant en DTB para ilustrar el contraste entre ambas formas de unidad de conciencia (cfr. esp. § 19, B 142: el juicio 'los cuerpos son pesados'; § 26, B 162-163: el caso del congelamiento del agua), todo parece indicar que son ciertas categorías las que hacen aquí la diferencia decisiva, a saber: las categorías que Kant denomina "dinámicas", por oposición a las "matemáticas", y, más específicamente aún, las categorías de la relación, es decir, sustancia, causalidad y acción recíproca. ${ }^{15}$ Esto permite señalizar dos tipos diferentes de casos que, por

${ }^{15}$ Esta interpretación se ve, a mi juicio, confirmada por el tratamiento que Kant lleva a cabo en la "Analítica de los principios" y, más específicamente, en las "Analogías de la experiencia", las cuales se refieren, justamente, a la posibilidad de aplicación de las categorías de relación a los objetos de la experiencia: aunque las categorías dinámicas y, en particular, las de relación, no poseen, a diferencia de las matemáticas, un uso constitutivo, sino uno meramente regulativo, no menos cierto es que sólo por medio de su intervención resulta posible dotar a los juicios de genuina referencia objetiva, pues lo propio de dichas categorías reside en el hecho de que su aplicación apunta a la existencia de los correspondientes objetos (cfr. A 160/B 199). En el caso de las categorías matemáticas, en cambio, Kant enfatiza que su empleo es constitutivo, y no meramente regulativo, pero sostiene, al mismo tiempo, que su aplicación no comporta por sí sola genuina referencia objetiva, pues se dirige, de modo directo, a la intuición pura, como tal, y no a los objetos de la experiencia, cuya existencia no se presupone todavía en dicha aplicación (cfr. A 160/B 199). Para una discusión más amplia de este punto y sus implicaciones para el modelo de constitución elaborado por Kant, véase Vigo 2004. Que la posición de Kant respecto de la conexión entre las nociones de 'enlace categorial' y 'unidad objetiva de la conciencia' no está libre de ambigüedades y oscilaciones es un punto que ha sido enfatizado, desde diferentes ángulos, por no pocos intérpre- 
razones diferentes y hasta cierto punto incluso opuestas, no satisfacen los requerimientos propios de la "unidad objetiva" de la conciencia, en el sentido más estricto del término, a saber: por un lado, 1) el caso de la determinación espontánea de la intuición pura por medio de las reglas de unificación provistas por las categorías, en general, y por las categorías matemáticas, en particular, determinación que por sí sola no involucra todavía referencia alguna a la existencia de objetos, tal como ocurre, para usar un ejemplo frecuente de Kant, en el caso del trazado de una línea; por otro lado, 2) el caso de aquellos enlaces de representaciones que, a pesar de involucrar conceptos empíricos, no quedan dotados, como tales, de genuina (pretensión de) validez objetiva, por cuanto no están basados en la aplicación de las categorías dinámicas y, más precisamente, de las categorías de relación. Con los casos del tipo 2) se corresponden los ejemplos a los que apela Kant más habitualmente, cuando se trata de oponer la "unidad objetiva" de la conciencia, en el sentido más estricto, a la "unidad meramente subjetiva", tal como ocurre, por caso, en el tratamiento de la distinción entre los así llamados "juicios de experiencia" (Erfahrungsurteile) y "juicios de percepción" (Wahrnehmungsurteile) en los §§ 18-21 de Prolegomena. A los casos del tipo 1) se acude, en cambio, cuando se trata de llamar la atención sobre la presencia de un nivel intermedio de constitución, en el cual se esboza por anticipado, por así decir, de modo espontáneo o ejecutivo, la forma de toda posible experiencia de objetos, en el modo del tipo peculiar de síntesis que pertenece a lo que Kant denomina la "imaginación productiva" (produktive Einbildungskraft), sin que dicha síntesis pueda producir por sí sola la presencia de ningún "objeto", en el sentido estricto del término. Se trata más precisamente, como es sabido, del tipo de síntesis que en el caso del ser humano, con su peculiar modalidad de receptividad sensible bajo la forma del tiempo (y el espacio), Kant denomina la "síntesis figurada" (figurliche Synthese) (cfr. esp. DTB § 24). Ésta guarda, desde el punto de vista sistemático, una conexión inmediata con el nivel de constitución tematizado en la doctrina del esquematismo (cfr. A 137-147/B 176-187) y también, al menos de

tes. Un diagnóstico clarificador de parte de las razones que conducen a algunas de tales ambigüedades y oscilaciones se encuentra en Hoppe 1983, quien llama la atención sobre la influencia negativa de lo que sería una insuficiente delimitación inicial, en el planteo kantiano, de dos complejos diferentes de problemas, a saber: el vinculado con la estructura de la referencia intencional a objetos, por una parte, y el vinculado con el origen de las pretensiones universales de validez del conocimiento, tal como queda sintetizado en la pregunta por la posibilidad de los juicios sintéticos a priori, por el otro (para la discusión de la concepción kantiana de la unidad objetiva de la conciencia, véase Hoppe 1983, esp. el cap. III).

Diánoia, vol. LIII, no. 61 (noviembre 2008). 
modo indirecto, con el nivel de constitución correspondiente al tipo de procedimiento de construcción conceptual que es propio de las matemáticas (cfr. A 137-142/ B 177-181; A 713-727/B 741-755). ${ }^{16}$

Más significativo desde el punto de vista que aquí interesa, y también menos reconocido en su verdadera importancia sistemática, es el modo en que Kant conecta la función de unificación correspondiente a los conceptos empíricos con el tratamiento de las formas de la unidad de la conciencia. El punto clave de acceso a esta importante conexión sistemática, que queda casi siempre relegada al trasfondo en la exposición de $K r V$, viene dado por la distinción entre lo que Kant denomina la "unidad analítica" y la "unidad sintética" de la conciencia, en el marco del tratamiento de la "unidad sintético-originaria de la apercepción" en el $\S 16$ de DTB. En el $\S 15$ Kant había sostenido, como se vio ya, que el enlace categorial se apoya en un enlace previo, en la medida en que su aplicación presupone ya la unidad de conceptos previamente dados, y había añadido, además, que la unidad aquí presupuesta no puede corresponder, como tal, a la regla de enlace provista por la categoría de unidad, porque la aplicación de ésta ya la presupone. Tal unidad debe buscarse, pues, "más arriba" (höher) que las categorías, por cuanto contiene el fundamento (Grund) de la unidad de diferentes conceptos en los juicios y, con ello, también de la posibilidad del entendimiento, incluso, en su uso lógico (cfr. B 131). Por ello, Kant sostiene que debe tratarse, en este caso, de una unidad de carácter cualitativo, y remite al previo tratamiento del concepto trascendental unum en el $\S 12$ (cfr. B 131). Inmediatamente después, en el $\S 16$, Kant tematiza lo que denomina la "unidad sintético-originaria de la apercepción", y elabora una argumentación destinada a poner de relieve la inevitable referencia a la unidad del 'yo pienso' que traen consigo todas y cada una de las representaciones, en virtud de su mero carácter de representaciones, lo cual conduce finalmente, en el $\S 17$, a la formulación del así llamado "principio (Grundsatz) de la unidad sintética de la apercepción",

\footnotetext{
${ }^{16}$ La ausencia de objeto en el nivel de la mera "síntesis figurada" se refleja, en el marco del tratamiento de la nada que cierra la "Anfibología", en el hecho de que, desde el punto de vista de las categorías dinámicas que desempeñan la función básica de referencia a la existencia del objeto - que no son otras que las categorías de relación-, la mera intuición pura aparezca caracterizada, considerada en su valencia privativa, en términos de la noción de mero ens imaginarium (= intuición vacía sin objeto) (cfr. A 291-293/B 347-349). La razón, como indica expresamente Kant, reside en el hecho de que, tomada por sí misma o, lo que es lo mismo, privada de sustancia (ohne Substanz), la intuición pura no es ella misma un objeto (cfr. A 291/B 347).
} 
como "principio supremo (das oberste Prinzip) de todo uso del entendimiento". Puesto que la argumentación desarrollada en los §§ 15-17 apunta, como un todo, justamente al establecimiento de dicho principio, resulta poco sorprendente que ya en la lectura de los $\S \S 15$ y 16 los intérpretes suelan enfatizar los aspectos más directamente vinculados con el modo peculiar en que Kant concibe la unidad del 'yo', en tanto fundada en la simple espontaneidad del pensar, entendido como la actividad misma de enlace. ${ }^{17}$ Mucho menos atención reciben, en cambio, la referencia expresa de Kant a la noción de unidad cualitativa en el $\S 15$, por un lado, y la importante nota referida a la distinción entre la "unidad analítica" y la "unidad sintética" de la conciencia en el $\S 16$, por el otro, lo cual conduce, no infrecuentemente, a que se pierda de vista la conexión sistemática entre ambos aspectos, por un lado, y de ambos con el tratamiento del trascendental unum en el $\S 12$, por el otro. La conexión resulta, sin embargo, manifiesta y sistemáticamente decisiva, como se verá enseguida.

En el § 16 Kant contrapone la "unidad analítica" y la "unidad sintética" de la conciencia, y ello con el propósito de avalar su tesis acerca del carácter originario del tipo de unidad sintética que introduce, de modo espontáneo, la apercepción trascendental, a través de la representación 'yo pienso'. En tal sentido, como queda señalado ya en el mismo texto del $\S 16$, Kant intenta mostrar que la unidad analítica de la conciencia presupone ya, como tal, su unidad sintética: la posibilidad de representarse la identidad (Identität) de la conciencia en una multiplicidad de representaciones sólo puede explicarse por referencia a la actividad sintética de la conciencia misma, en la medida en que el 'yo' no se limita meramente a acompañar (begleiten) a todas y cada una de las representaciones dadas en la conciencia, sino que, además, las añade activamente unas a otras (eine zu den anderen hinzusetze) y se hace, al mismo tiempo, consciente de tal síntesis. Por tanto, la "unidad analítica" de la apercepción (die analytische Einheit der Apperzeption), explica Kant, sólo resulta posible, como tal, bajo la presuposición de algún tipo de "unidad sintética" (unter der Voraussetzung irgendeiner synthetischen (sc. Einheit); las cursivas son mías) (B 133). La nota añadida al $\S 16$

${ }^{17}$ En la actividad sintética de la (auto)conciencia que adquiere expresión en el principio del 'yo pienso' Kant identifica el fundamento último de carácter protológico que da cuenta de la posibilidad de toda forma específica de enlace representacional, entre otras, también aquellas que quedan documentadas en las diferentes posibles formas del juicio. Para una brillante discusión de la estructura de la fundamentación protológica de las formas lógicas avistada aquí por Kant, véase ahora Enskat 2007. 
ilustra el punto acudiendo al ejemplo de los conceptos universales. Kant explica que la unidad analítica de la conciencia es un momento que acompaña necesariamente a todos los conceptos universales. Cuando pienso, por ejemplo, el rojo, en general, me represento una determinación (Beschaffenheit) que como nota (Merkmal) puede ser hallada por todas partes (irgend woran), es decir, en múltiples objetos, o bien puede quedar enlazada con muchas otras representaciones (mit anderen Vorstellungen verbunden). Ahora bien, para que una representación pueda ser pensada como común a otras muchas, se requiere que sea pensada como perteneciente a éstas, y éstas, a la vez, como no completamente idénticas a ella, sino como diferentes de ella, lo cual supone que la primera deba ser pensada primero en unidad sintética (in synthetischer Einheit) con esas otras múltiples representaciones, no importa si éstas son efectivas o meramente posibles. Tal unidad sintética constituye, pues, un requerimiento previo de la unidad analítica de conciencia que concede a una determinada representación el estatuto de un conceptus communis, lo que equivale a decir, explica Kant, que este tipo de unidad analítica sólo resulta posible, como tal, por medio de una (posible) unidad sintética, pensada ya de antemano (vermöge einer vorausgedachten möglichen synthetischen Einheit) (B 133-134). ${ }^{18}$

Desde el punto de vista que aquí interesa, hay que poner de relieve al menos tres aspectos en esta explicación ofrecida por Kant. En primer lugar, el tipo de unidad sintética aquí tematizado nada tiene que ver con el enlace categorial, como lo muestra ya el simple hecho de que Kant se oriente a partir de ejemplos que, como el de los conceptos universales, no pueden ser analogados al caso de las reglas de síntesis provistas por

\footnotetext{
${ }^{18}$ La referencia de Kant a un tipo de unidad sintética subyacente a la unidad analítica propia de los conceptos universales resulta, como tal, todavía neutral respecto de la cuestión de si, en cada caso, el enlace de una determinada nota con otras representaciones ha de verse, desde el punto de vista de la comprensión de los conceptos involucrados, como de carácter "analítico" o "sintético", en el sentido lógico habitual. En efecto, el 'rojo' puede ser pensado como enlazado con 'manzana' o bien con 'color', pero mientras que en el primer caso, desde el punto de vista lógico, el enlace es sintético, en el segundo es analítico, por cuanto 'color' constituye el género de 'rojo', que es una de sus especies. Por lo mismo, la distinción de las dos formas de unidad de conciencia designadas como la unidad analítica y la unidad sintética no debe ser confundida tampoco con la distinción habitual entre el enlace analítico y el enlace sintético en el juicio. Para este punto, véase las correctas observaciones en Baum 1986, pp. 22 ss., quien critica la identificación de ambas llevada a cabo por G. Patzig. Para el tratamiento kantiano de la distinción entre 'notas analíticas' y 'notas sintéticas' y, en conexión con ella, de la distinción entre 'notas coordinadas' y 'notas subordinadas' en las lecciones de lógica, véase Capozzi 2002, pp. 489 ss.
} 
las categorías. Significativo, en este sentido, es el hecho de que Kant se refiera a "algún tipo" de unidad sintética como presupuesto de la unidad analítica, lo que da a entender claramente que no tiene en vista aquí específicamente el tipo de enlace que da lugar al tipo peculiar de unidad de conciencia que corresponde a la así llamada "unidad objetiva" de la conciencia. ${ }^{19}$

En segundo lugar, y en directa conexión con lo anterior, hay que llamar la atención también sobre el hecho de que cuando recurre a la noción de 'nota', Kant tiene en vista claramente dos posibles tipos de enlace: por un lado, el que permite reconocer la presencia de un mismo rasgo en múltiples objetos ( $v$.gr., el color rojo en una manzana, un vestido, etc.) y, por otro, el que permite vincular una misma nota con otros muchos conceptos. En el primer caso, se tiene una relación entre una nota conceptual y múltilples posibles notas intuitivas; en el segundo, en cambio, se trata de las relaciones que mantiene una determinada nota conceptual con la multiplicidad de otras notas conceptuales (conceptos) a las que es común. En ambos casos, sin embargo, se trata de formas de enlace que poseen un carácter prejudicativo.

En tercer lugar, por último, hay que enfatizar el hecho, cuya importancia sistemática no puede ser exagerada, de que para ilustrar el modo en que el 'yo pienso' opera la unidad sintética de representaciones, que está a la base de cualquier posible modo de la unidad analítica de la conciencia, Kant apele expresamente al ejemplo provisto por el tipo de unidad que es propia de los conceptos universales, más concretamente, de conceptos empíricos como 'rojo', y no al caso de los juicios. Por cierto, esto no debe malentenderse, como ha ocurrido con alguna frecuencia, en el sentido de que Kant pretendiera sugerir que la unidad de la apercepción, como tal, debe ser asimilada, sin más, al tipo de unidad que corresponde a un concepto universal. ${ }^{20}$ Tal suposición es inviable, ya por la sencilla razón de que el tipo de unidad que ejemplifica el con-

${ }^{19}$ Para una interpretación del pasaje en esta misma línea, véase Baum 1986, pp. 32 ss., quien distingue claramente las diferentes formas de unidad de conciencia avistadas por Kant y vincula de modo expreso la unidad objetiva con las diversas formas del enlace categorial. Para el sentido de la referencia a "algún tipo" de enlace, véase ahora también Prien 2006, pp. 137 s.

${ }^{20}$ Véase, en tal sentido, la certera advertencia de Rosales 2000, p. 164: "Entgegen häufigen Mißdeutungen gilt es festzuhalten, daß das Ich auch kein Allgemeines im Sinne eines Begriffes (eines Vorgestelltes) ist, sondern ein Gemeinsames im Sinne eines Vorstellenden, das alle Vorstellungen umgreift" ["Contra frecuentes malentendidos hay que mantener que el 'yo' no es algo universal, en el sentido de un concepto, sino algo común, en el sentido de un 〈sujeto〉 del representar que abarca todas las representaciones"].

Diánoia, vol. LIII, no. 61 (noviembre 2008). 
cepto cae, como tal, del lado del contenido objetivo representado en cada caso, es decir, del lado del objeto del conocimiento, mientras que la unidad sintético-originaria de la apercepción remite, en cambio, a la unidad del sujeto que por medio de su actividad sintética hace posible, como tal, toda experiencia y todo conocimiento de objetos. ${ }^{21}$ Más bien, en la comparación con el tipo de unidad que representa el concepto Kant pretende marcar tan sólo una suerte de paralelismo estructural que vincula la relación entre la unidad del 'yo' y la multiplicidad de sus representaciones, por un lado, y la relación entre la unidad del concepto y la multiplicidad de las representaciones a las que queda o puede quedar vinculado, por el otro: en ambos casos la unidad sintética, que es, como tal, de carácter activo, es condición posibilitante de la referencia común de una representación, del tipo que fuera, a cierta multiplicidad dada, y ello de modo tal que dicha unidad sintética debe ser ya pensada de antemano, al menos como posible unidad, en todo acto que apunte al reconocimiento de la presencia de algo idéntico en una multiplicidad, sea ésta efectiva o tan sólo potencialmente dada (v.gr., el 'yo' junto a todas mis representaciones; la misma 'nota' en diferentes objetos o conceptos). ${ }^{22}$ El paralelismo así señalado, comprende inseparablemente dos aspectos que dan cuenta de la peculiar mediación entre unidad y multiplicidad que Kant tiene en vista aquí, a saber: en el caso de los conceptos universales, el enlace sintético, al menos potencial, con diferentes objetos o bien con diferentes conceptos permite reconducir la multiplicidad de esos objetos o conceptos a la unidad del concepto bajo el cual caen, y, viceversa, es sólo con referencia a tal multiplicidad

${ }^{21}$ Para el problema de la conexión de la distinción entre 'unidad analítica' y 'unidad sintética' en el $\S 16$ con la teoría kantiana del objeto del conocimiento, que desempeña posteriormente un papel decisivo en el argumento de DTB a partir del $\S 17$, véanse las buenas observaciones en Caimi 2007, pp. 38 s. Para la conexión entre la unidad analítica y la identidad (numérica) del 'yo', en el sentido aquí señalado, véase también Prien 2006, pp. 135 ss.

${ }^{22}$ Como señala acertadamente Baum (1986, pp. 100 s.), el énfasis de Kant sobre el hecho de que la unidad sintética pensada de antemano no necesita ser una unidad efectiva entre representaciones ya dadas, sino que puede tomar la forma de una unidad sintética sólo posible referida, como tal, a posibles representaciones, apunta a reforzar el paralelismo entre el caso de la unidad del concepto y el caso de la unidad sintético-originaria de la apercepción, pues también de ésta afirma Kant en el $\S 16$ de DTB que la referencia a la unidad del 'yo' en todas y cada una de las representaciones no necesita adquirir la forma de una autoconciencia expresa: el 'yo pienso' meramente tiene que poder acompañar todas mis representaciones ( $\mathrm{mu} \Omega$ alle meine Vorstellungen begleiten können), a fin de que éstas puedan ser mías (cfr. B 131-132). 
como el concepto, que opera como regla de unificación, puede ser considerado en su carácter de universalidad, en cuanto que es idéntico o invariable en cada una de sus instancias; de modo comparable, en el caso del 'yo', sólo el enlace activo de representaciones en una conciencia -que, como tal, va siempre acompañado, al menos potencialmente, también de la correspondiente conciencia de dicho enlace- permite referir la multiplicidad de las representaciones a la unidad del 'yo', y, viceversa, también reconocer, con referencia a dicha multiplicidad de representaciones, la identidad del 'yo', en cuanto que está presente junto a todas y cada una de ellas.

Ahora bien, aunque no se apunta de este modo a una simple homologación de la unidad del 'yo' y la unidad del concepto, no menos cierto es, sin embargo, que la unidad del concepto documenta, por así decir, al modo de un producto cristalizado, el tipo peculiar de enlace sintético originariamente activo que lleva a cabo el 'yo' en el pensar. Este último, el 'yo' pensante, no comparece de modo directo, sino sólo en y a través de sus productos. Y justamente el hecho de que, una vez cristalizados, tales productos de la actividad sintética del 'yo' adquieran la consistencia propia de contenidos representacionales, independientes y diversos entre sí, contribuye, de modo decisivo, a encubrir la referencia de todos ellos, en su misma génesis, a la propia actividad sintético originaria del 'yo'. Pero, como el propio Kant enfatiza al final de la nota añadida al $\S 16$ de DTB, la unidad sintético originaria de la apercepción, en cuanto que está supuesta en toda otra posible forma de unidad de conciencia, provee, en definitiva, el "punto más alto" (der höchste Punkt) del cual pende todo posible uso del entendimiento, incluidas la lógica formal, como un todo, y la propia filosofía trascendental (B 134). La actividad del pensar, en todas sus posibles formas de realización efectiva, debe concebirse, en definitiva, como una actividad de carácter unificador. Dicho de otro modo: en su carácter más general, el pensamiento constituye una función de unidad. Sin embargo, la conexión que Kant establece con el caso de la unidad del concepto muestra que el problema relativo a la unidad de la conciencia no puede ser estrechado al ámbito del enlace judicativo, en general, y mucho menos aún al ámbito del peculiar tipo de enlace judicativo que posee carácter categorial. De hecho, mientras que el principio de la unidad sintética de la apercepción es presentado como el principio supremo de todo uso del entendimiento ( $c f r$. DTB $\S 17$ ), la unidad objetiva de la conciencia es tratada, en cambio, como el producto de uno de los posibles modos de enlace que el entendimiento produce espontáneamente, a saber: de aquel que tiene lugar a través de los diferentes posibles modos de enlace judicativo, allí

Diánoia, vol. LIII, no. 61 (noviembre 2008). 
donde éstos son empleados no sólo como funciones de unificación de carácter meramente lógico, sino también, al mismo tiempo, como reglas para el enlace de lo intuitivamente dado y cumplen entonces una función de carácter categorial. Desde este punto de vista, el juicio (objetivo) no es otra cosa que el modo en que determinados conocimientos son conducidos a la unidad objetiva de la apercepción (cfr. § 19, esp. B 141). De forma inversa, respecto de los conceptos universales, como tales, el paralelismo establecido por Kant pone de relieve que el tipo de unidad que éstos representan tampoco sería posible sin la referencia a la unidad sintética de la apercepción. Esto muestra que los conceptos universales, en general, y los conceptos empíricos, en particular, remiten en su génesis misma a principios trascendentales, vinculados con la unidad sintético-originaria de la apercepción. La conexión que Kant establece entre ésta y la noción de unidad cualitativa del $\S 12$ adquiere, así, una relevancia insospechada, también desde el punto de vista de la tematización de las condiciones apriorísticas que dan cuenta de la posibilidad de la formación originaria de juicios objetivos.

\section{Conceptos trascendentales como principios regulativos de la formación de conceptos empíricos}

Si lo anterior resulta convincente, entonces hay muy buenas razones para afirmar que, lejos de ser arbitraria o puramente exterior, la analogía que Kant establece en el $\S 16$ de DTB entre la unidad del 'yo' y la unidad del concepto, rectamente entendida, proporciona un atisbo clave con referencia a aspectos centrales de la teoría kantiana de la constitución de la experiencia, en la medida en que pone de relieve el papel posibilitante que desempeña la noción de unidad, en el sentido cualitativo de carácter supracategorial, tanto desde el punto de vista de la unidad del sujeto, como desde el punto de vista de la unidad del objeto de la experiencia: antes de la intervención de cualquier enlace categorial, la síntesis activa introduce ya unidad, y ello en el doble sentido de la referencia de todas las representaciones al sujeto de la experiencia y de la unificación de la multiplicidad de representaciones, intuitivas o conceptuales, bajo otras representaciones más abarcadoras. No hace falta reiterar que el enlace que constituye propiamente una genuina experiencia de objetos, tal como Kant la tematiza bajo la noción de "unidad objetiva" de la conciencia, sólo puede ser efectuado por medio de la intervención de las reglas de enlace provistas por las categorías y, más específicamente, por las categorías de relación. Pero, como también se ha dicho, este tipo particular de enlace, que adquiere 
expresión en las diversas formas del juicio, se opera necesariamente sobre conceptos ya dados, lo cual se refleja en el hecho de que la materia de los juicios objetivos viene dada por determinados conceptos empíricos, a través de los cuales el juicio mismo se refiere a su objeto. Por lo mismo, la unidad propia del concepto constituye, como tal, un presupuesto básico del genuino conocimiento objetivo. Y, por tanto, no puede sorprender demasiado que Kant pregunte por su posible fundamento apriorístico y descubra así la conexión subyacente con la unidad sintético originaria de la apercepción, que provee, como se dijo, el principio último de todo posible uso del entendimiento, es decir, también de aquel que subyace a la formación originaria de conceptos empíricos y a su posterior empleo como regla de las intuiciones.

Esta última es, precisamente, la conexión a la que apunta el tratamiento de los conceptos trascendentales en el $\S 12$. Allí discute Kant la tesis de la metafísica tradicional que establece la convertibilidad de las nociones de ens, por un lado, y de unum, verum y bonum, por otro (cfr. B 113). Kant legitima dicha tesis desde el punto de vista propio de la filosofía trascendental, pero para ello debe rechazar la pretensión de otorgarle una función constitutiva a los conceptos trascendentales de unidad, verdad y bondad: no se trata aquí de supuestos predicados que se apliquen de modo directo a todas las cosas, sino, más bien, de exigencias (Erfördernisse) y criterios (Kriterien) lógicos que debe satisfacer todo conocimiento de cosas (B 113). Dicho de otro modo: las notas de unidad, verdad y bondad, que proveen criterios que deben satisfacer los conceptos, corresponden a las cosas, sólo en cuanto que son conocidas, y ello justamente en la medida en que las cosas son conocidas, en cada caso, a través de determinados conceptos. ${ }^{23}$

Como se echa de ver, al igual que en el caso del tratamiento de los conceptos de reflexión en la "Anfibología", también en el caso del § 12 la estrategia general de Kant para hacer justicia a la función básica de determinados conceptos relevados por la tradición, sin tener que asumir por ello las consecuencias de lo que sería, a su juicio, una apresurada objetivación metafísica de lo que no puede tener el carácter de objeto, ${ }^{24}$

${ }^{23}$ Véase Metaphysik $L_{2}$, p. 631: "Trascendental etwas betrachten geschieht blos in Beziehung auf den Begriff dieses Dinges" ["Considerar algo trascendentalmente tiene lugar sólo con referencia al concepto de esa cosa"].

${ }^{24}$ En este sentido, véase la declaración expresa en Metaphysik Schön, p. 495: "Quodlibet est unum, verum, bonum. Dieser Satz der Scholastischen Philosophie wurde ganz im transßendentalen Sinne genommen und nicht im metaphysischen. In jenem Betracht werden dem Subject nur Praedicate in Ansehung seines bestimmten Wesens, in diesem aber in Ansehung seines Begriffs beygelegt" ["Quodlibet est

Diánoia, vol. LIII, no. 61 (noviembre 2008). 
consiste en otorgarles una función orientativa o regulativa vinculada a determinados procesos de mediación reflexiva que subyacen a las operaciones sintéticas que dan lugar a los actos cognitivos, tal como éstos tienen lugar en el caso de los genuinos juicios objetivos.

Un segundo aspecto importante de continuidad con el tratamiento de la "Anfibología" viene dado por el hecho de que tampoco en el caso de los conceptos trascendentales la adscripción de una función puramente heurístico-regulativa, y no constitutiva, conduce, sin más, a una desvinculación de dichos conceptos respecto de las categorías. Por el contrario, Kant asume que así como los cuatro pares de conceptos de reflexión ( $v . g r$., 'identidad'/'diferencia', 'concordancia'/'discordancia', 'interior'/'exterior', y 'materia'/'forma') están en correspondencia, cada uno de ellos, con uno de los cuatro tipos de categorías ( $v . g r$., cantidad, cualidad, relación y modalidad, respectivamente) (cfr. A 262-266/B 317-322), así también, en el caso de los tres conceptos trascendentales unum, verum y bonum, hay que asumir cierta vinculación con determinadas categorías. La diferencia estriba, sin embargo, en que en este caso ya no se trata de distintos tipos de categorías, sino, más bien, de las tres categorías de cantidad, y ello de modo tal que a unum subyace la categoría de unidad (Einheit), a verum la de pluralidad (Vielheit) y a bonum la de totalidad (Allheit) (cfr. B 114). Evidentemente, Kant no ve contradicción alguna entre la suposición de que a cada concepto trascendental subyace una determinada categoría de cantidad, por un lado, y la afirmación realizada en el $\S 16$ de DTB, según la cual la unidad cualitativa del $\S 12$ se sitúa, como tal, por encima de la unidad categorial, por el otro. La razón, como se verá, tiene relación directa

unum, verum, bonum. Esta proposición de la filosofía escolástica ha sido tomada exclusivamente en el sentido trascendental, y no en el metafísico. En aquel modo de considerar, los predicados se atribuyen al sujeto sólo con respecto a su esencia determinada, en éste, en cambio, con respecto a su concepto"]. La confusión de estas reglas lógicas con principios metafísicos se explica del siguiente modo: "Wie kommt das (sc. la mencionada confusión) aber nun hierher? Weil man oft logische Regeln zu Bedingungen der Objekte gemacht hat. In der transßendental Philosophie suchen wir die Principien der Vernunft auf. Das sind aber nicht Objekte, sondern blos die Bedingungen, unter welchen die Erkenntnis der Objekte möglich ist. Diese Bedingungen werde ich also nicht den Sachen selbst beylegen müssen, sondern sie kommen allein den Prinzipien zu" ["Pero ¿de dónde surge aquí $\langle s c$. la mencionada confusión $\rangle$ ? De que a menudo se ha convertido las reglas lógicas en condiciones de los objetos. En la filosofía trascendental rastreamos los principios de la razón. Pero éstos no son objetos, sino meramente las condiciones bajo las cuales es posible el conocimiento de los objetos. Por lo tanto, no deberé atribuir esas condiciones a las cosas mismas, sino que sólo les pertenecen a los principios"].

Diánoia, vol. LIII, no. 61 (noviembre 2008). 
con el modo en que Kant interpreta el significado de los conceptos trascendentales y, en particular, el de la noción trascendental de unidad, pues se trata, en todos los casos, de nociones que orientan determinados procesos reflexivos de la facultad del juicio, y que, como tales, no dan lugar a ningún tipo de acto determinante, lo cual supone que la categoría subyacente en cada caso es enfocada, por así decir, en una dirección diferente a la propia del uso determinante, y ello de modo tal que la categoría provee ahora un criterio orientativo de referencia para el correspondiente proceso de reflexión, pero no queda, como tal, incorporada en su resultado como un elemento que formara parte del contenido de éste, al menos no en el modo en que ello ocurre en el caso del uso propiamente constitutivo. ${ }^{25}$

Por último, importa subrayar que ni el rechazo de la función constitutiva de los conceptos trascendentales, ni la vinculación con el ámbito de las categorías de cantidad, que, en principio, trae consigo una pérdida del carácter transgenérico o transcategorial asignado tradicionalmente a dichos conceptos, implica de suyo el abandono de lo que, en definitiva, es la intuición nuclear de la doctrina tradicional de los trascendentales. Dicha intuición nuclear no es otra que la de la validez de las determinaciones trascendentales de unidad, verdad y bondad para todos y cada uno de los "objetos". Y Kant cree poder conservarla, con la sustancial diferencia, sin embargo, de que los "objetos" de los que ahora se trata no son ya las cosas consideradas en sí mismas, sino, más bien, sólo en cuanto pueden ser conocidas, y ello justamente en

${ }^{25}$ Este punto se conecta de modo directo con el problema, sistemáticamente central, de las funciones de la facultad del juicio reflexivo en las cuales la reflexión tiene lugar bajo la orientación que prescribe la referencia a categorías. Una reconstrucción de conjunto de esta problemática se encuentra en Kugelstadt 1998, quien considera especialmente el caso de los conceptos de reflexión (cfr. pp. 24 ss.), también en conexión con el tratamiento de la formación de conceptos (cfr. pp. 242-303). Se echa de menos, en cambio, una consideración expresa del caso de los conceptos trascendentales. Lo que podría llamarse la "diferencia de dirección" en la consideración de las categorías de cantidad que Kant tiene en vista en el caso concreto del $\S 12$ se pone de manifiesto ya en el simple hecho de que la multiplicidad unificada a la luz de los criterios provistos por dichas categorías debe verse aquí como heterogénea ( $c f r$. B 115). Esto supone una importante divergencia respecto del empleo constitutivo de esas mismas categorías como reglas de síntesis. En efecto, como el propio Kant enfatiza de modo expreso en el tratamiento de la "Analítica de los principios", el empleo constitutivo de las categorías matemáticas, en general, y de las categorías de la cantidad, en particular, apunta a la unidad sintética de lo homogéneo de la intuición, más precisamente, de la multiplicidad intuitiva homogénea provista a priori por espacio y tiempo (cfr. A 162/B 201 y nota).

Diánoia, vol. LIII, no. 61 (noviembre 2008). 
la medida en que el acceso cognitivo a ellas sólo puede tener lugar a través de conceptos.

Veamos ahora brevemente cómo Kant reinterpreta, dentro de esta estrategia general, el significado de cada uno de los tres conceptos trascendentales.

1) Respecto de unum, Kant explica que todo conocimiento involucra unidad cualitativa (qualitative Einheit), en la medida en que implica unidad de concepto (Einheit des Begriffs). Este empleo de la noción de unidad no debe confundirse con el empleo categorial de carácter constitutivo que da lugar a la cuantificación universal del juicio. Por el contrario, se trata, en este caso, de una unidad de carácter cualitativo, en la medida en que no posee alcance extensional, sino que refiere, más bien, a la comprensión del concepto involucrado, en virtud de la cual éste queda circunscrito como un concepto determinado y, con ello, también como diferente de otros. ${ }^{26}$ En tal sentido, Kant compara este tipo de unidad con la unidad del tema en una obra de teatro o bien en un discurso (cfr. B 114). ${ }^{27}$

2) Respecto de verum, la explicación de Kant conecta la noción trascendental de verdad, a través de la relación entre fundamento (Grund) y consecuencias (Folgen), con la noción de realidad objetiva (objekti$v e$ Realität), en el sentido preciso de la noción de 'realidad' (de 'res'), que remite no a la existencia efectiva (Wirklichkeit) del objeto, sino, más bien, al contenido descriptivo del concepto, entendido como un conjunto de notas (Merkmale): cuantas más consecuencias verdaderas, en el sentido de las notas que pertenecen a un concepto como

${ }^{26}$ En el mismo sentido, en Metaphysik $L_{2}$ se caracteriza la noción en términos de la "unidad de lo determinable" (Einheit des Bestimmbaren), que es propia de todo objeto de conocimiento ( $c f r$. Metaphysik $L_{2}$, p. 556). Véase también Metaphysik Volckmann, p. 415.

${ }^{27}$ Véase también Metaphysik Schön, p. 497, donde se alude al uso de la noción de unidad en sentido formal (formaliter), y se pone como ejemplo los casos en los que se habla de la "unidad" (Einheit) de un cuadro, una conferencia o un concierto. Estos ejemplos permiten comprender un poco mejor también la razón por la cual Kant apela a la noción de unidad cualitativa para dar cuenta del peculiar tipo de unidad que corresponde al 'yo' trascendental, en la medida en que éste, como sujeto último de toda posible experiencia, no puede ser él mismo objeto de ninguna experiencia, ni cae, por lo mismo, bajo ningún concepto empírico. En efecto, tampoco el "tema" de un cuadro, una obra de teatro, etc., que es lo que permite dar cuenta propiamente de su unidad, puede identificarse, sin más, con ninguna de las partes del todo cuya unidad explica, aunque no menos cierto es que comparece, como tal, a través de ellas y está en cierto modo presente junto a todas y cada una de ellas. 
a su fundamento común, tanto más realidad objetiva posee dicho concepto. A esto alude, explica Kant, la noción cualitativa de pluralidad (qualitative Vielheit) (cfr. B 114). Como se explica de modo más detenido en las lecciones de metafísica, la aplicación de la noción de verdad apunta, en este caso, a la concordancia (Übereinstimmung) de las diferentes notas, entre sí y también con el concepto (esencia) al que pertenecen. ${ }^{28}$

3) Respecto de bonum, Kant explica que, en el caso de la totalidad en sentido cualitativo (qualitative Vollständigkeit/Totalität), se trata de aquella perfección (Vollkommenheit) que consiste en el hecho de que la pluralidad de las determinaciones (notas) es referida, nuevamente, a la unidad del correspondiente concepto (Einheit des Begriffes), de modo tal que dicha pluralidad sólo coincide completamente con dicho concepto, y con ningún otro ( $c f r$. B 114). Como se explica en otro contexto, esta noción trascendental de perfección no se corresponde ni con la física, que remite a la adecuación de las representaciones empíricas, ni con la metafísica, que remite a la noción de grados de realidad. La noción trascendental de perfección remite al hecho de que toda cosa contiene necesariamente todo aquello que debe contener para ser la cosa que precisamente es. Por lo mismo, esta noción, a diferencia de las dos anteriores, no admite grados: toda cosa es perfecta, en sentido trascendental. ${ }^{29}$

En su función específica, estos conceptos operan como "criterios puramente lógicos de la posibilidad del conocimiento, en general" (logische Kriterien der Möglichkeit der Erkenntnis überhaupt) (cfr. B 114-115), y ello en la medida en que, como se vio, el conocimiento de cosas viene posibilitado por la intervención de los correspondientes conceptos. Ahora bien, la peculiaridad del empleo lógico-criteriológico de las categorías de cantidad aquí subyacente consiste, como señala Kant de modo expreso, en que dichas categorías no se aplican en este caso para hacer posible el enlace sintético de una diversidad homogénea dada en la intuición, como ocurre allí donde son empleadas de modo constitutivo para la generación de una cantidad dada (Erzeugung des Quantums). Más bien, las funciones de unificación provistas por tales categorías son empleadas aquí para orientar procesos reflexivos que apuntan a la conexión en cierta unidad de conciencia (Verknüpfung in einem Bewußt-

\footnotetext{
${ }^{28}$ Véase Metaphysik $L_{2}$, p. 556; Metaphysik Volckmann, p. 415; Metaphysik Schön, p. 496.

${ }^{29}$ Véase Metaphysik $L_{2}$, p. 556; Metaphysik Volckmann, p. 415.
} 
sein) de una diversidad heterogénea de fragmentos diversos de conocimiento (Erkenntnisstücke) (cfr. B 115), es decir, en definitiva, de notas. Que se trata de requerimientos meramente lógicos del conocimiento se explica ya por el simple hecho de que en el empleo de los conceptos de trascendentales (cualitativos) de unidad, pluralidad y totalidad se deja por completo de lado el aspecto correspondiente a la referencia objetiva de dichos conceptos, para limitarse a proceder con ellos de un modo tal que sólo supone las reglas lógicas universales que dan cuenta de la posibilidad de la concordancia del conocimiento consigo mismo (cfr. B 115-116), como, por ejemplo, el principio de no contradicción. ${ }^{30}$ Desde este punto de vista, que es el propio de la lógica de los conceptos, tal como la entiende Kant, la tríada formada por los trascendentales unum-verum-bonum puede verse, al mismo tiempo, referida a una determinada secuencia de pasos subyacente al proceso de formación originaria de los conceptos, en particular, de los conceptos empíricos, que constituyen las unidades básicas en las que se apoyan los actos propios de la síntesis cognitiva, tal como éstos tienen lugar en el juicio objetivo. En dicha secuencia, la unidad conceptual aparece, primero, como una mera exigencia formal que debe satisfacer todo posible conocimiento de cosas, en la medida en que éste tiene lugar siempre a través de conceptos (unum). Tal unidad conceptual opera, en un segundo paso, como criterio que orienta la (posible) unificación de una multiplicidad de notas dada (verum), para, finalmente, quedar "puesta", vale decir, realizada efectivamente como unidad, a través de la (retro)referencia común de todas y cada una de las notas así unificadas a la unidad del concepto al que pertenecen (bonum). ${ }^{31}$

${ }^{30}$ La apelación al principio de no contradicción desempeña un papel expreso en el tratamiento de verum como pluralidad cualitativa en las lecciones de metafísica, pues la posible concordancia de las diversas notas entre sí y con el correspondiente concepto se rige, justamente, por dicho principio. Para este aspecto, véase esp. Metaphysik Schön, pp. 496 s., donde se explica, además, que la diferencia entre una cosa (Ding) y lo que como cosa carece de posibilidad lógica (Unding) se relaciona con el hecho de que en el segundo caso se tiene un conjunto de notas que contiene elementos contradictorios entre sí.

${ }^{31}$ Comprendida en términos de la secuencia así esbozada, la tríada unum-verumbonum refleja el escalonamiento propio de las categorías de unidad, pluralidad y totalidad, las cuales, aunque irreductibles entre sí, configuran, a juicio de Kant, una especie de unidad sistemática que recuerda, en algunos de sus rasgos, al tipo de estructura que tiene en vista Hegel, cuando apela a su noción de síntesis dialéctica. Como el propio Kant sugiere en el $\S 11$ de $K r V$, la totalidad puede ser caracterizada, en tal sentido, como la multiplicidad pensada como unidad (cfr. B 111). Para una consideración de las consecuencias que se podrían derivar de este peculiar trata- 
Ahora bien, como muestran los ejemplos de aplicación en concreto de estos criterios lógicos que ofrece el texto del $\S 12$, lo que la concepción aquí esbozada tiene primariamente en vista son dos aspectos básicos de la lógica de los conceptos, tal como el propio Kant la desarrolla en el Logikcorpus y la expone también, de modo fragmentario, en la "Doctrina del método" de $\mathrm{KrV}$, a saber: el problema de la determinación conceptual, que se expresa de modo particularmente nítido en la teoría de la definición, por un lado, y el problema de la explicación empírica y la generación de teorías, tal como ésta se expresa ejemplarmente en la problemática de las hipótesis, por el otro. ${ }^{32}$ Así, la definición, en tanto despliega el contenido de un concepto dado, alberga en sí los tres momentos cualitativos de la unidad del concepto, la verdad de sus diversas consecuencias (notas) y la totalidad de lo que resulta derivable de dicho concepto, y provee, de este modo, el criterio de la posibilidad (Kriterium der Möglichkeit) de un concepto, aunque, por cierto, no todavía del objeto correspondiente. Por lo mismo, la definición contiene, como tal, todo lo necesario para la producción o el establecimiento (Herstellung) de dicho concepto. De modo semejante, en el establecimiento de una determinada hipótesis se emplea como criterio la comprensibilidad del principio explicativo así supuesto, lo cual implica su unidad, que remite al hecho de que no reclama hipótesis auxiliares, su verdad, en el sentido de la correspondencia consigo mismo y con la experiencia, y también la totalidad de dicho principio explicativo, que no remite a nada más que lo que contiene la hipótesis ( $c f r$ B 115). ${ }^{33}$

miento secuencial de la tríada de conceptos trascendentales, véase Baumanns 1997, pp. 254 ss., quien pone en el centro de la atención, sobre todo, el modo en que dicho tratamiento de los conceptos trascendentales se vincularía con la concepción kantiana relativa al origen de las formas básicas del juicio ( $v . g r$. , la distinción entre juicio categórico, hipotético y disyuntivo). Baumanns llega tan lejos como para ver en la tríada unum-verum-bonum el fundamento explicativo último de la distinción de las capacidades lógicas fundamentales, esto es, entendimiento (Verstand), facultad del juicio (Urteilskraft) y razón (Vernunft) (cfr. p. 257).

${ }^{32}$ Para ambos aspectos, véase la amplia discusión en Natterer 2003, pp. 353-366, quien considera también el material relevante contenido en el Logikcorpus. Como acertadamente señala Natterer, la importancia que Kant asigna en su lógica de los conceptos al problema de la definición y la esencia lógica, por un lado, y al de las hipótesis, por el otro, delata claramente la persistente vinculación con el trasfondo provisto por la doctrina aristotélica de la ciencia. Para el tratamiento kantiano del problema de la esencia lógica y el de las hipótesis en el Logikcorpus, véase Capozzi 2002, pp. 501-540 y 669-685.

${ }^{33}$ Para el tratamiento kantiano de los requerimientos que deben satisfacer las hipótesis, véase Cappozzi 2002, pp. 668 ss. Tales requerimientos son, en general, los tres mencionados también en el $\S 12$, a saber: 1) la suposición de la hipótesis

Diánoia, vol. LIII, no. 61 (noviembre 2008). 
En el caso concreto de la función que desempeñan los conceptos trascendentales en la formación originaria de conceptos empíricos, que proveen la materia de los juicios objetivos, hay que llamar la atención sobre el hecho, no siempre adecuadamente considerado, de que los procesos reflexivos de comparación de conceptos que Kant tematiza en el tratamiento de la "Anfibología" recaen sobre conceptos ya dados de antemano, cada uno de los cuales debe ser ya, como tal, posible, vale decir, debe ser un concepto unitario, internamente determinado y, como tal, también diferente de otros. ${ }^{34}$ En cambio, los procesos de comparación, reflexión y abstracción que Kant tematiza en el Logikcorpus para dar cuenta de la generación de conceptos no se aplican, como tales, a conceptos ya dados, al menos no en el mismo sentido que los procesos de reflexión lógica y reflexión trascendental descritos en la "Anfibología". Por lo mismo, la comparación, que involucra en este caso también la relación entre notas intuitivas y conceptuales, apunta aquí a la formación originaria de aquellas unidades en las que se apoyan, posteriormente, los procesos reflexivos subyacentes a la operación del juicio, como tal. Ello explica que, a diferencia de lo que ocurre en el caso de los conceptos de reflexión, sea un único tipo de categoría el que provee los correspondientes criterios a partir de los cuales se orientan estos peculiares procesos reflexivos. Y esto quiere decir, a su vez, que lo que está en juego aquí no es todavía la consideración de relaciones de inclusión, exclusión, etc., entre conceptos, sino, más bien, algo tan elemental como la posibilidad misma de la articulación unitaria de determinados conjuntos de notas.

No resulta, pues, azaroso que Kant identifique la noción de "unidad", en el sentido cualitativo, como aquella que en sus tres posibles modulaciones, correspondientes a las tres categorías de cantidad, provee la pauta orientativa requerida para abrir el espacio en el que se mueven los correspondientes procesos de comparación, reflexión y selección abstractiva de las notas. Justamente el papel que cumple aquí la noción de abstracción muestra hasta qué punto se trata, en este caso, de otro tipo de proceso de mediación reflexiva: en el caso de la formación

debe ser posible (cfr. también $K U \S 90$, p. 446, citado por Cappozzi); 2) la relación de consecuencia lógica debe ser establecida del modo correcto, tal que las consecuencias se sigan efectivamente de la condición supuesta como fundamento; y 3) la hipótesis debe ser única, y no debe apoyarse en hipótesis auxiliares.

${ }^{34}$ Para una excelente discusión de conjunto de la concepción kantiana relativa a la comparación de conceptos como presupuesto del enlace judicativo, en el marco del tratamiento de los conceptos de reflexión de la "Anfibología", véase Longuenesse 1998a, pp. 136-161. 
originaria de un concepto, el dejar de lado aspectos del objeto y notas conceptuales, con arreglo a la pauta que proveen los correspondientes principios lógicos, constituye, como tal, un aspecto positivo en la propia generación de unidades conceptuales, mientras que en el caso de la reflexión conducente al juicio la constatación de conflicto entre diferentes conceptos sólo puede conducir a la generación de un determinado tipo de juicio, que no es otro que el negativo, pues a partir de conceptos que estén en conflicto lógico no pueden formarse juicios afirmativos verdaderos (cfr. A 262/B 317-318). ${ }^{35}$

\section{A modo de conclusión}

Si la anterior discusión de la posición esbozada por Kant en su tratamiento de los conceptos trascendentales, la unidad cualitativa y la unidad de la conciencia resulta aceptable, habrá que admitir que el denso y poco claro desarrollo contenido en el $\S 12$ realiza un aporte sustancial para la reconstrucción de la concepción kantiana acerca de las condiciones apriorísticas subyacentes a la formación originaria de genuinos juicios objetivos. Ya en su orientación general el tratamiento de los conceptos de unum, verum y bonum en el $\S 12$ DTB delata su clara semejanza de inspiración con el tratamiento de los conceptos de reflexión de la "Anfibología". Pero si lo dicho antes respecto de la diferente estructura y el diferente objetivo de los procesos de mediación reflexiva involucrados en uno y otro caso es cierto, entonces habrá que admitir que lo que se tematiza en el $\S 12$ es un conjunto de condiciones diferentes e incluso más básicas, en la medida en que, entre otros posibles modos de empleo, apuntan también, y principalmente, a dar cuenta de la posibilidad de la formación originaria de aquellos conteni-

\footnotetext{
${ }^{35}$ En su tratamiento, muy breve y más bien colateral, del problema de la formación de conceptos, Longuenesse (1998a, pp. 161-166) no hace debida justicia a este aspecto, al quedar excesivamente apegada al paradigma explicativo provisto por el tratamiento de los conceptos de reflexión de la "Anfibología" y al uso de la noción de comparación que Kant realiza en dicho contexto. Tratándose de una investigación que, por su altísimo nivel de calidad, puede considerarse ya poco menos que canónica, la lección que debe extraerse de este hecho habla, probablemente, de cierta persistencia residual de la influencia negativa que ha ejercido la tendencia tradicional a ver el tratamiento de los conceptos trascendentales del § 12 como un añadido marginal, carente de genuina proyección sistemática. Kugelstadt (1998, pp. 243-312), en su detallado y altamente diferenciado examen de la concepción kantiana de la formación de conceptos, tampoco hace justicia a este aspecto, al orientarse exclusivamente a partir de la problemática vinculada con los conceptos de reflexión.
} 
dos representacionales sobre los cuales recae, posteriormente, el enlace categorial constitutivo de un juicio objetivo.

Ahora bien, así como en el caso de la "Anfibología" la posición de Kant, con su requerimiento de doble mediación reflexiva ( $v . g r$, reflexión lógica y reflexión trascendental), sólo resulta plausible si se restringe el alcance de las condiciones así delineadas al caso de la formación originaria de juicios objetivos, algo análogo habrá que decir también para el caso de los requerimientos reflexivos tematizados en el § 12. En efecto, se trata aquí de requerimientos que sólo debe satisfacer la formación originaria de conceptos, y no el empleo competente de los términos del lenguaje, que pueden ser aprendidos, poseídos y empleados como signos representantes de determinados contenidos conceptuales, sin necesidad de reejecutar de modo expreso los procesos de comparación, reflexión y abstracción que dan origen a los correspondientes conceptos, e incluso sin poseer tales conceptos de un modo verdaderamente claro y diferenciado, tal como éste se reflejaría en la capacidad de proveer la correspondiente definición. ${ }^{36}$

Puestos en conexión todos estos elementos, se perfila nítidamente un cuadro de conjunto de la teoría kantiana de la constitución que le confiere un sorprendente grado de diferenciación, y que la pone en mucho mejores condiciones para dar cuenta de un modo plausible de las complejas relaciones que vinculan al conocimiento, en el sentido estricto que remite a los actos categorialmente mediados propios de la síntesis judicativa, con niveles más básicos y menos elaborados de constitución de la experiencia, correspondientes al acceso perceptivo a lo inmediatamente dado y a su articulación conceptual más elemental, en las diferentes modalidades propias de la síntesis prejudicativa. ${ }^{37}$

\footnotetext{
${ }^{36}$ Para el tratamiento kantiano de la relación entre concepto, esencia lógica y signo lingüístico, véase Capozzi 2002, pp. 503 ss.; para la concepción kantiana acerca de los grados del contenido objetivo del conocimiento, con las distinciones referidas a modos más o menos completos del concebir, véase pp. 525-540.

${ }^{37}$ Una importante cuestión ulterior, que no puede ser discutida aquí, concierne al modo preciso en que Kant concibe la relación entre el proceso de la formación originaria de conceptos empíricos, por un lado, y la posesión de las reglas de síntesis que hacen posible la síntesis judicativa, en particular, de la categoría de sustancia, que, como se sabe, corresponde en el caso de Kant a la relación de inherencia y subsistencia, por el otro. La importancia del punto se advierte cuando se considera el hecho de que la formación de conceptos empíricos tiene lugar ya, como tal, en términos de la diferencia entre conceptos que corresponden a determinaciones sustantivas (v.gr., 'perro') y conceptos que corresponden a determinaciones no sustantivas o bien no genuinamente sustantivas ( $v . g r$., 'blanco' y 'blancura', respectivamente), lo cual explica que ciertos conceptos empíricos estén, por así decir, cortados a la
} 


\section{BIBLIOGRAFÍA}

\section{I. Kant \\ Jäsche Logik}

$\mathrm{KrV}$

$K U$

Logik Blomberg

Metaphysik Dohna

Metaphysik $L_{2}$

Metaphysik Schön

Metaphysik Volckmann

Prolegomena
Logik. Ein Handbuch zu Vorlesungen (1800), ed. G.B. Jäsche, Akademie-Ausgabe, vol. IX, Berlín, 1923; y reimpr., pp. 1-150, 503-508.

Kritik der reinen Vernunft $\left({ }^{2} 1787,1781\right)$, ed. J. Timmermann y H. Klemme, Hamburgo, 1998.

Kritik der Urteilskraft (1790), ed. H.F. Klemme, notas de P. Giordanetti, Hamburgo, 2001; citado por la paginación de la Akademie-Ausgabe, vol. V, ed. W. Windelband, Berlín, ${ }^{2} 1913$, pp. 165-485.

Logik Blomberg (hacia 1771?), en Kants Vorlesungen, vol. I: Vorlesungen über Logik, 1. Teil, ed. G. Lehman, Akademie-Ausgabe, vol. XXIV/1, Berlín, 1966, pp. 7301.

Allgemeine Metaphysik Dohna, Kants Vorlesungen, vol. V: Vorlesungen über Metaphysik und Rationaltheologie, Zweite Hälfte, Erster Teil, ed. G. Lehman, Akademie-Ausgabe, vol. XXVIII/2, 1, pp. 611-704.

Allgemeine Metaphysik $L_{2}$, vol. V: Vorlesungen über Metaphysik und Rationaltheologie, Zweite Hälfte, Erster Teil, ed. G. Lehman, Akademie-Ausgabe vol. XXVIII, pp. 525-609.

Allgemeine Metaphysik von Schön, vol. V: Vorlesungen über Metaphysik und Rationaltheologie, Erste Hälfte, ed. G. Lehman, Akademie-Ausgabe vol. XXVIII/1, pp. 461-524.

Allgemeine Metaphysik Volckmann, vol. V: Vorlesungen über Metaphysik und Rationaltheologie, Erste Hälfte, ed. G. Lehman, Akademie-Ausgabe vol. XXVIII/1, pp. 351-460.

Prolegomena zu einer jeden künftigen Metaphysik, die als Wissenschaft wird auftreten können (1783), ed. K. Pollok, Hamburgo, 2001; citado por la paginación de la Akademie-Ausgabe, vol. IV, ed. B. Erdmann, Berlín, ${ }^{2} 1911$ (= 1903), pp. 253-383.

medida para ocupar, más bien, el lugar del sujeto del juicio, mientras que otros aparezcan habitualmente del lado del predicado. En su tratamiento de las diferencias fundamentales dentro del ámbito de la lógica de los conceptos, Kant discute muchos aspectos importantes vinculados con la génesis conceptual, aunque, hasta donde alcanzo a ver, no aborda de modo sistemático la cuestión antes planteada. Su posición sobre este punto, por tanto, debe ser reconstruida a partir de material que se encuentra bastante disperso.

Diánoia, vol. LIII, no. 61 (noviembre 2008). 
Reflexionen

Reflexionen aus dem Nachlaß (1753-1803); vol. XVI: Reflexionen zur Logik, ed. E. Adickes (1924); vol. XVII-XVIII: Reflexionen zur Metaphysik (1924/1928), ed. E. Adickes; Akademie-Ausgabe; citados por número de reflexión, seguido indicación del número de volumen en romanos y el de página en arábigos.

\section{Bibliografía secundaria}

Bärthlein, K., 1976, "Von den 'Transzendentalphilosophie der Alten' zu der Kants", Archiv für Geschichte der Philosophie, vol. 58, no. 4, pp. 353-392.

Baum, M., 1986, Deduktion und Beweis in Kants Transzendentalphilosophie, Hain Verlag bei Athenäum, Königstein.

Baumanns, P., 1997, Kants Philosophie der Erkenntnis. Durchgehender Kommentar zu den Hauptkapiteln der "Kritik der reinen Vernunft", Königshausen und Neumann, Würzburg.

Caimi, M., 2007, Leçons sur Kant. La déduction transcendantale dans la deuxième édition de la 'Critique de la raison pure', Publications de la Sorbonne, París.

Capozzi, M., 2002, Kant e la logica, Bibliopolis, Nápoles, vol. 1.

Enskat, R., 2007, "Kants Protologik", en Lorenz 2007, pp. 185-210.

Hoppe, H., 1983, Synthesis bei Kant. Das Problem der Verbindung von Vorstellungen und ihrer Gegenstandsbeziehung in der "Kritik der reinen Vernunft", Walter de Gruyter, Berlín/Nueva York.

Kemp Smith, N., 1923, A Commentary to Kant's 'Critique of Pure Reason', Londres, $1979={ }^{2} 1923$.

Knittermeyer, H., 1920, Der Terminus 'transcendental' in seiner historischen Entwicklung bis zu Kant, Phil. Diss., Marburgo.

Kugelstadt, M., 1998, Synthetische Reflexion. Zur Stellung einer nach Kategorien reflektierenden Urteilskraft in Kants theoretischer Philosophie, Walter de Gruyter, Berlín/Nueva York.

Longuenesse, B., 2005a, "Kant on A Priori Concepts: The Metaphysical Deduction of the Categories", en Longuenesse 2005b, pp. 81-116.

- 2005b, Kant on the Human Standpoint, Cambridge University Press, Cambridge.

_ 1998a, Kant and the Capacity to Judge. Sensibility and Discursivity in the Transcendental Analytic of the 'Critique of Pure Reason', Princeton University Press, Princeton/Oxford, 2000 (= 1998); versión inglesa revisada de: Kant et le pouvoir de juger. Sensibilité et discursivité dans l'Analytique transcendantale de la 'Critique de la Raison Pure', Presses Universitaires de France, París, 1993.

_ $1998 \mathrm{~b}$, "The Divisions of the Transcendental Logic and the Leading Threat", en Mohr y Willascheck 1998, pp. 131-158.

Lorenz, A. (comp.), 2007, Transzendentalphilosophie heute. Breslauer Kant-Symposium 2004, Königshausen und Neumann, Würzburg. 
Mohr, G. y M. Willascheck (comps.), 1998, Immanuel Kant, Kritik der reinen Vernunft, Akademie Verlag, Berlín.

Natterer, P., 2003, Systematischer Kommentar zur 'Kritik der reinen Vernunft', Berlín/Nueva York.

Paton, H.J., 1936, Kant's Metaphysics of Experience. A Commentary on the First Half of the "Kritik der reinen Vernunft", George Allen and Unwin, Londres, vols. I-II.

Prien, B., 2006, Kants Logik der Begriffe. Die Begriffslehre der formalen und transzendentalen Logik Kants, Walter de Gruyter, Berlín/Nueva York.

Rosales, A., 2000, Sein und Subjektivität bei Kant. Zum subjektiven Ursprung der Kategorien, Walter de Gruyter, Berlín/Nueva York.

Stuhlmann-Laeisz, R., 1976, Kants Logik. Eine Interpretation auf der Grundlage von Vorlesungen, veröffentlichten Werken und Nachlaß, Walter de Gruyter, Berlín/Nueva York.

Vigo, A.G., 2006, "Reflexión y juicio", Diánoia (México), vol. 51, no. 57, pp. 2764.

—, 2004 , "Determinación y reflexión", Anuario Filosófico, vol. 37, no. 3 (2004), pp. 749-795.

Wieland, W., 2001, Urteil und Gefühl. Kants Theorie der Urteilskraft, Vandenhoeck und Ruprecht, Gotinga.

Wolff, M., 1995, Die Vollständigkeit der kantischen Urteilstafel. Mit einem Essay über Freges Begriffsschrift, Klostermann, Fráncfort del Meno.

Wolff-Metternich, B.S. von, 1995, Die Überwindung des mathematischen Erkenntnisideals. Kants Grenzbestimmung von Mathematik und Philosophie, Walter de Gruyter, Berlín/Nueva York.

Recibido el 27 de junio de 2007; aceptado el 5 de mayo de 2008.

Diánoia, vol. LIII, no. 61 (noviembre 2008). 